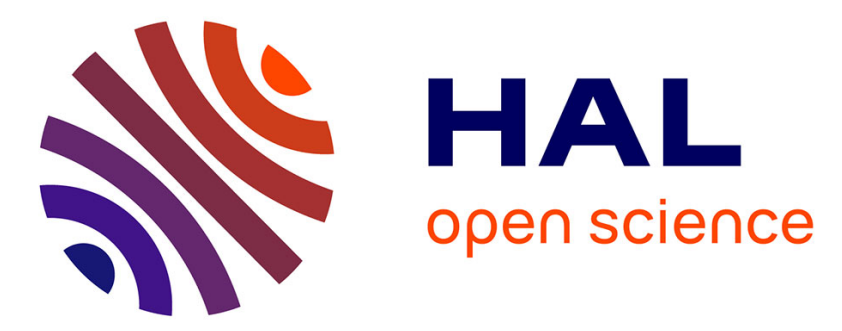

\title{
Metal-based BODIPY derivatives as multimodal tools for life sciences
}

Benoit Bertrand, Kévin Passador, Christine Goze, Franck Denat, Ewen Bodio, Michèle Salmain

\section{> To cite this version:}

Benoit Bertrand, Kévin Passador, Christine Goze, Franck Denat, Ewen Bodio, et al.. Metal-based BODIPY derivatives as multimodal tools for life sciences. Coordination Chemistry Reviews, 2018, 358, pp.108-124. 10.1016/j.ccr.2017.12.007 . hal-01693664

\section{HAL Id: hal-01693664 https://hal.sorbonne-universite.fr/hal-01693664}

Submitted on 26 Jan 2018

HAL is a multi-disciplinary open access archive for the deposit and dissemination of scientific research documents, whether they are published or not. The documents may come from teaching and research institutions in France or abroad, or from public or private research centers.
L'archive ouverte pluridisciplinaire HAL, est destinée au dépôt et à la diffusion de documents scientifiques de niveau recherche, publiés ou non, émanant des établissements d'enseignement et de recherche français ou étrangers, des laboratoires publics ou privés. 


\title{
Metal-based BODIPY derivatives as multimodal tools for life sciences
}

Benoit Bertrand, ${ }^{a, b}$ Kévin Passador, ${ }^{b}$ Christine Goze, ${ }^{c}$ Franck Denat, ${ }^{c}$ Ewen Bodio, ${ }^{c}, *$ Michèle Salmain ${ }^{b, *}$

a School of Chemistry, University of East Anglia, Norwich, NR4 7TJ, United Kingdom.

${ }^{\mathrm{b}}$ Sorbonne Universités, UPMC Univ Paris 06, CNRS, Institut Parisien de Chimie Moléculaire (IPCM), 4 place Jussieu 75005 Paris, France

' ICMUB UMR 6302, CNRS, Univ. Bourgogne Franche-Comté, F-21000 Dijon, France.

* Corresponding authors: Tel: +33 1 44276732, email address: michele.salmain@upmc.fr (MS) ; Tel: +33 3803960 76, email address: ewen.bodio@u-bourgogne.fr (EB)

\begin{abstract}
Nowadays, 4,4-difluoro-4-bora-3a,4a-diaza-s-indacene - better known as BODIPY ${ }^{\bullet}$ - is at the forefront of fluorophores for life sciences. Indeed, its high brightness, its tunable excitation and emission wavelengths along with its high chemical and photochemical stability draw more and more the interest of researchers. In the last decade, chemists have taken advantage of the versatility of the synthesis of BODIPY to design sophisticated objects. This review focuses on the different recent studies dealing with the conception of metal-based-BODIPY derivatives for medical purposes. More precisely, emphasis is put on the use of BODIPY derivatives for the elaboration of BODIPY-based theranostics, multimodal imaging probes, and photodynamic therapy sensitizers.
\end{abstract}

\footnotetext{
- Abbreviations: acac, acetylacetonate; BMDC, bone marrow derived dendritic cell; BODIPY, boron dipyrromethene, 4,4-difluoro-4-bora-3a,4a-diaza-s-indacene; bpy, 2,2'-dipyridyl; BSA, bovine serum albumin; cat, catechol; CLSM, confocal laser scanning microscopy; CT, computed tomography; DFO, deferoxamine; DOTAGA, 1,4,7,10-tetraazacyclododecane-1-glutaric acid-4,7,10-triacetic acid; DOTA, 1,4,7,10-tetraazacyclododecane-1,4,7,10-tetraacetic acid; dppz, dipyridophenazine; DTPA, diethylene triamine tetracetic acid; DTT, dithiotreitol; FA, folic acid; Fc, ferrocenyl; FDA, food and drug administration; GRPR, gastrin-releasing peptide receptor; HER2, human epithelial growth factor receptor 2; HIF, hypoxia inducing factor; ICP-MS, inductively coupled plasma mass spectrometry; ISC, intersystem crossing; LDH, lactate dehydrogenase; LN, lymph node; LPS, lipopolysaccharide; $m A b$, monoclonal antibody; MOF, metal-organic framework; MOMIP, monomolecular multimodal imaging probe; MRI, magnetic resonance imaging; NIR, near infrared; NODAGA, 1,4,7-triazacyclononane,1-glutaric acid4,7-acetic acid ; NP, nanoparticle; NPA, $p$-nitrophenylalanine; Oc, octreotide; PACT, photo-activated chemotherapy; PDI, photodynamic inactivation; PDT, photodynamic therapy; PEG, poly(ethylene glycol); $\mathrm{PEI}$, poly(ethylenimine); PeT, photoinduced electron transfer; $\mathrm{PET}$, positron emission tomography; $\mathrm{PI}$, phototoxicity index; ppy, 2-phenylpyridine; PS, photosensitizer; PTT, photothermal therapy; pyda-T, 2,4diamino-6-(2-pyridyl)-1,3,5-triazine; ROS, reactive oxygen species; sc-DNA, supercoiled DNA; SPECT, single photon emission computed tomography; SPION, superparamagnetic iron oxide nanoparticle; SRIXE, synchrotron radiation induced X-ray emission; SSTR2, somatostatin receptor 2; TCO, transcyclooctene; TrxR, thioredoxin reductase; Tz, tetrazine; WT, wild-type.
} 


\section{Keywords}

BODIPY, bimodal Imaging, fluorescence, metal-based drugs, theranostics, photodynamic therapy

\section{Content}

1. Introduction

2. Theranostics: one imaging modality and one therapeutic modality

2.1. Labeling of reported metal-based pharmacophores

2.2. Bioconjugated theranostics

2.3. Near IR BODIPY-metal complexes

3. Metal-BODIPY bioconjugates for photodynamic therapy

4. Bimodal imaging probes

4.1. BODIPY based optical / PET or SPECT imaging probes

4.2. BODIPY-based bimodal optical imaging / MRI agents

5. Conclusion and perspectives

Acknowledgement

References 


\section{Introduction}

This last decade witnessed the advent of "multifunctionality way of life" and research is no exception. A single tool needs to display different applications, to collect numerous information... In medicine, this trend leads to new fields of research such as "theranostics" or "multimodal imaging". Indeed, it is no longer enough to "simply" conceive a cytotoxic molecule, you need to track it all along its lifetime, and the designed probe should provide information both in vitro and in vivo. In this context, an increasing number of researchers are developing molecular or nanomolecular objects associating a metal complex to a luminescence probe. The metal complex can play the role of a cytotoxic agent or an imaging probe - scintigraphic probe in case of radioactive metal or Magnetic Resonance Imaging (MRI) probe in case of a paramagnetic one - while the luminophore enables optical imaging and/or can induce a phototoxic sensitization.

Optical imaging is the most used imaging modality in association with these multifunctional objects due to its ease of use, its low cost, and its superiority for in vitro studies. Numerous luminescent probes are available, however, for almost 20 years now, BODIPY dyes have turned out to be among the most useful molecules for fluorescent labeling of biomolecules in living cells [1].

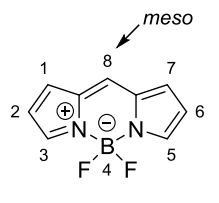

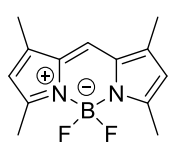

$\mathrm{EtOH}, \Phi 0.80$

$\lambda_{\max \text { abs }} 505 \mathrm{~nm}$

$\lambda_{\text {max emiss }} 516 \mathrm{~nm}$

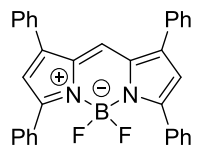

DCM, $\Phi 1.00$

$\lambda_{\max \text { abs }} 564 \mathrm{~nm}$

Figure 1. Structure of the BODIPY core and representative BODIPY derivatives

Historically, the BODIPY core (Figure 1) was first synthesized by Treibs and Kreuzer in 1968,[2] but its first use as a fluorescent label for bioactive ligands was reported in 1989 [3]. Since that period, the number of papers and patents related to BODIPY has not ceased to increase each year (Figure 2).

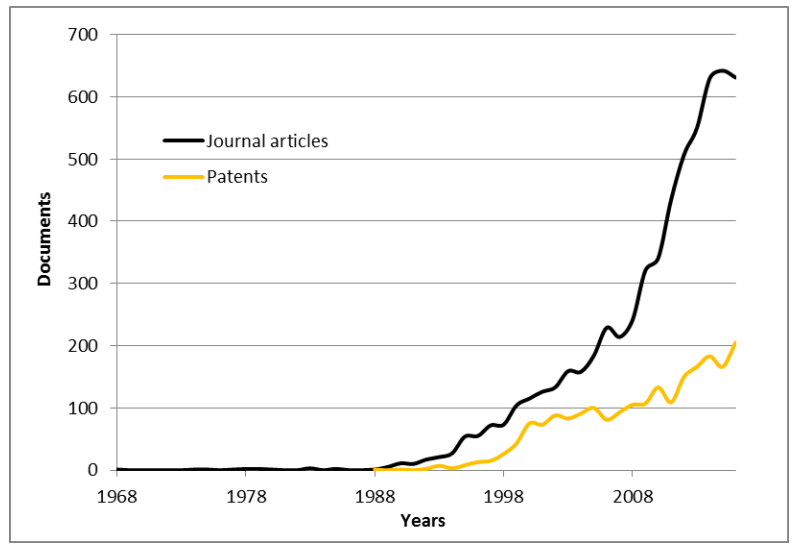

Figure 2. Occurrence of BODIPY in journal articles and patents as extracted from the CAS Scifinder ${ }^{T M}$ database

The unprecedented success of BODIPY dyes can be explained by their excellent optical properties. In practice, they display strong absorbance and relatively sharp fluorescence peaks with high 
quantum yields. Moreover, the extraordinarily rich chemistry they offer played a crucial role in their development,[4-6] and consequently they found applications in various domains such as material science [7]. Regarding biological applications, the great stability of BODIPY under physiological conditions and their insensitivity towards $\mathrm{pH}$ variations make them a choice candidate for numerous fluorescent labeling purposes. Additionally, their resistance to photobleaching proved to be significantly higher than other classical fluorophores, which is often appreciable for imaging experiments [8]. Through all possible modifications of the BODIPY core, their optical properties are easily tunable as broad postfunctionalization is allowed. Thanks to this, numerous different chemical functions have been successfully grafted on BODIPY. However, BODIPY dyes suffer from several drawbacks, notably their high lipophilicity, along with their typical absorption and emission wavelengths located around $500 \mathrm{~nm}$. Indeed, NIR (near-infrared region 650-900 nm) probes are preferred for in vivo fluorescence imaging experiments, and water solubility is often a critical parameter for internalization of bioactive compounds. Notwithstanding, great advances have been made to improve water solubility of BODIPY, especially by introducing ionic groups on it [9]. As for the fluorescence properties, numerous modifications of BODIPYs were reported in order to get red-shifted emission. Here, it is noteworthy that the more recent aza-BODIPY family (Figure 3), first described in 1993,[10] won fame in NIR emission and is currently attracting an increasing interest [11].
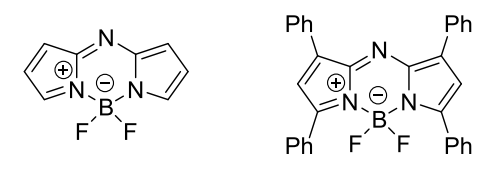

aza-BODIPY core

$$
\begin{gathered}
\mathrm{CHCl}_{3}, \Phi 0.34 \\
\lambda_{\max \text { abs }} 650 \mathrm{~nm} \\
\lambda_{\max \text { emiss }} 672 \mathrm{~nm}
\end{gathered}
$$

Figure 3. Structure of aza-BODIPY

All along the 30 past years of constant development, the chemistry of BODIPY has become rich and extensively described. Among the various associations, which have already been studied between them and other classes of molecules, we chose to focus on metal-based BODIPY derivatives and their use as tools for life sciences. The approaches developed in these studies differ from the numerous works dealing with BODIPY sensors for detecting metals in cells [12]. We will also not develop the few metalBODIPY conjugates, that have been designed as turn-on fluorescent biosensors for selective detection of NO or CO production in cells $[13,14]$. We believe that the combination between this versatile fluorophore and some metallic complexes has already brought some great advances, and will probably lead to innovative imaging methods and efficient theranostic agents.

This review deals with the association of a metal complex and a BODIPY in the same entity

(1) to take advantage of the unique photophysical properties of BODIPYs to track the fate of metallodrugs or metallodrug candidates in vitro or even in vivo and possibly get insight into their mechanism of action;

(2) to confer or increase photosensitizing properties to BODIPYs thanks to the heavy atom effect

(3) to use the physical properties of some metal ions to build up bimodal imaging probes.

These points will be successively reviewed in the following sections of the manuscript. 


\section{Theranostics: one imaging modality and one therapeutic modality}

The quest for novel transition metal-based drugs is a very active area of research especially in the area of cancer chemotherapy and readers are strongly advised to consult recently published reviews, should they wish to have an overview of the current trends in the field [15-19]. Compared to purely organic molecules, metal complexes display distinct features such as ligand exchange ability, multiple oxidation states and unique redox chemistry, resulting in original mechanisms of action [20].

Although the field of modern medicinal inorganic / organometallic chemistry finds its origin in the seminal work of P. Erhlich with Salvarsan for the treatment of syphilis, the first meaningful breakthrough in the field of metal-based drugs was the discovery of the antineoplastic activity of cisplatin (Figure 4) by Rosenberg in the 1960s. The success story of cisplatin continues since a large proportion of chemotherapeutic protocols involves administration of cisplatin in association with other antitumor drugs. Despite its remarkable pharmacological properties, cisplatin suffers from drawbacks which translate into severe side effects and resistance development. Other platinum-based molecules have been approved like carboplatin and more recently oxaliplatin for colorectal cancer. Hundreds of other Pt(II) as well as $\mathrm{Pt}(\mathrm{IV})$ complexes and palladium(II) have been synthesized in research laboratories and tested for their anticancer activity but none of them have been marketed to date [21]. The goldbased metallodrug Auranofin, (2,3,4,6-tetra- $O$-acetyl-1-(thio- $K S)-\beta$-Dglucopyranosato)(triethylphosphane)gold(I) (Figure 4) is another metal-based drug that was approved by the FDA in 1985 for the treatment of rheumatoid arthritis. Although auranofin is no longer the medication of choice for this pathology, its repurposing is currently under study to treat other pathologies like leukemia [22].

In the field of cancer chemotherapy, inorganic and organometallic complexes of other transition metals have been extensively studied in the past 20 years with emphasis put on (arene)-ruthenium(II) and ruthenium(III) complexes. Two representatives of the Ru(III) class of compounds have reached clinical trials, namely NAMI-A [23] and KP1019 [24] as antimetastatic drugs. Some (arene)-Ru(II) RAPTAtype complexes such as RAPTA-C (Figure 4) have also a good chance to future clinical development owing to their unique properties [25]. Following auranofin, other $A u(I)$ as well as $A u(I I I)$ complexes have attracted much attention,[26,27] especially as $\mathrm{N}$-heterocyclic carbene complexes for the organometallic representatives [28]. Several ranges of iridium(III), rhodium(I) or (III) and osmium(II) complexes are also extensively investigated and some of them display promising anticancer activity in vitro [29-31]. Finally, ferrocenyl derivatives display attractive biological activities, some of them being intimately linked to the unique redox properties of the ferrocene entity [32,33].

\subsection{Labeling of reported metal-based pharmacophores.}

Being able to ascertain and quantify the uptake of metal-based drugs is of major importance considering that in, many cases, poor metal uptake has been reported to be the primary cause of inactivity [34-38]. Moreover, to be able to localize the place or organelles where the metallodrugs accumulate is of particular interest for the understanding of their mechanism of action. To do so, methodologies to quantify and localize metal complexes without probes have been established using synchrotron radiation-induce X-ray emission (SRIXE) and inductively coupled plasma-mass spectrometry techniques (ICP-MS). However, in the case of cisplatin [39], opposite results have been obtained concerning its intracellular localization depending of what technique had been used. Indeed, after incubation of cisplatin with human ovarian cancer cells (A2780) for $24 \mathrm{~h}$, platinum was observed by SRIXE 
to accumulate almost only in the nucleus [40]; while platinum quantification in different cellular fractions by ICP-MS showed the highest amount of platinum in the cytoplasm and particulates [41]. Moreover, SRIXE and ICP-MS are really expensive and time-consuming techniques, and therefore they can hardly be considered as "routine" techniques for the quantification and localization of the different metals.

On the contrary, optical imaging is one of the cheapest imaging techniques and displays the great advantage to be a noninvasive method and to enable real time imaging. Thus, in order to observe simply the intracellular accumulation site of metal-based drugs, different fluorescent-labeled analogues have been synthesized and tested. When compared with similar fluorescein-containing platinum complexes, the BODIPY analogues proved to have antiproliferative properties closer by the ones of cisplatin making them more reliable for mechanistic studies [42]. This reason, combined to the attractive photoluminescent properties of BODIPYs, has made them very popular for labeling metallodrugs. Up to now, many established pharmacophores have been coupled to BODIPY derivatives in order to study their uptake and intracellular localization (Figure 4). Self-assemblies of metal-based BODIPY derivatives have also been recently reported as potential theranostics [43-45]. The neutral analogue of cisplatin 2.1-2 was demonstrated to induce DNA damages in ovarian carcinoma cells, associated with a 100-times reduced activity with respect to cisplatin [46]. The cationic analogue of cisplatin 2.1-3 appeared to have an antiproliferative activity only reduced three or four times with respect to cisplatin depending on the studied cell lines [47]. This demonstrates the impact of the BODIPY fluorophore on the biological properties of known pharmacophores. Complexes 2.1-2, 2.1-3 and 2.1-4 were visualized inside cancer cells using fluorescence microscopy. In all cases, the compounds were found to accumulate in mitochondria [46-48]. This localization in the mitochondria was confirmed by the quantification of platinum by ICP-MS which revealed platinum bound to mitochondrial DNA after incubation with 2.1-2 and 2.1-3 [47,48]. Such intracellular distribution has also been reported with fluorescein-labeled cisplatin analogues [49]. Moreover, the presence of a BODIPY fluorophore enabled the study of the pharmacokinetic of complex 2.1-2 by time-course fluorescence microscopy in mouse blood vessel and tumor tissue demonstrating a plasma kinetics similar to cisplatin and carboplatin [46].

Complex BODI-Ru-0 is a BODIPY-labeled version of the antimetastatic complex RAPTA-C (Figure 4) $[50,51]$. Interestingly, this compound demonstrated an improved antiproliferative activity compared to RAPTA-C. Visualization of the uptake of BODI-Ru-0 by confocal microscopy revealed a fast entry into the cancer cells (after $2 \mathrm{~h}$ of incubation) associated with a non-specific spreading through the cells very similarly to the BODIPY-phosphane ligand. This suggests that uptake and accumulation in cells might be driven by the BODIPY ligand [51]. 

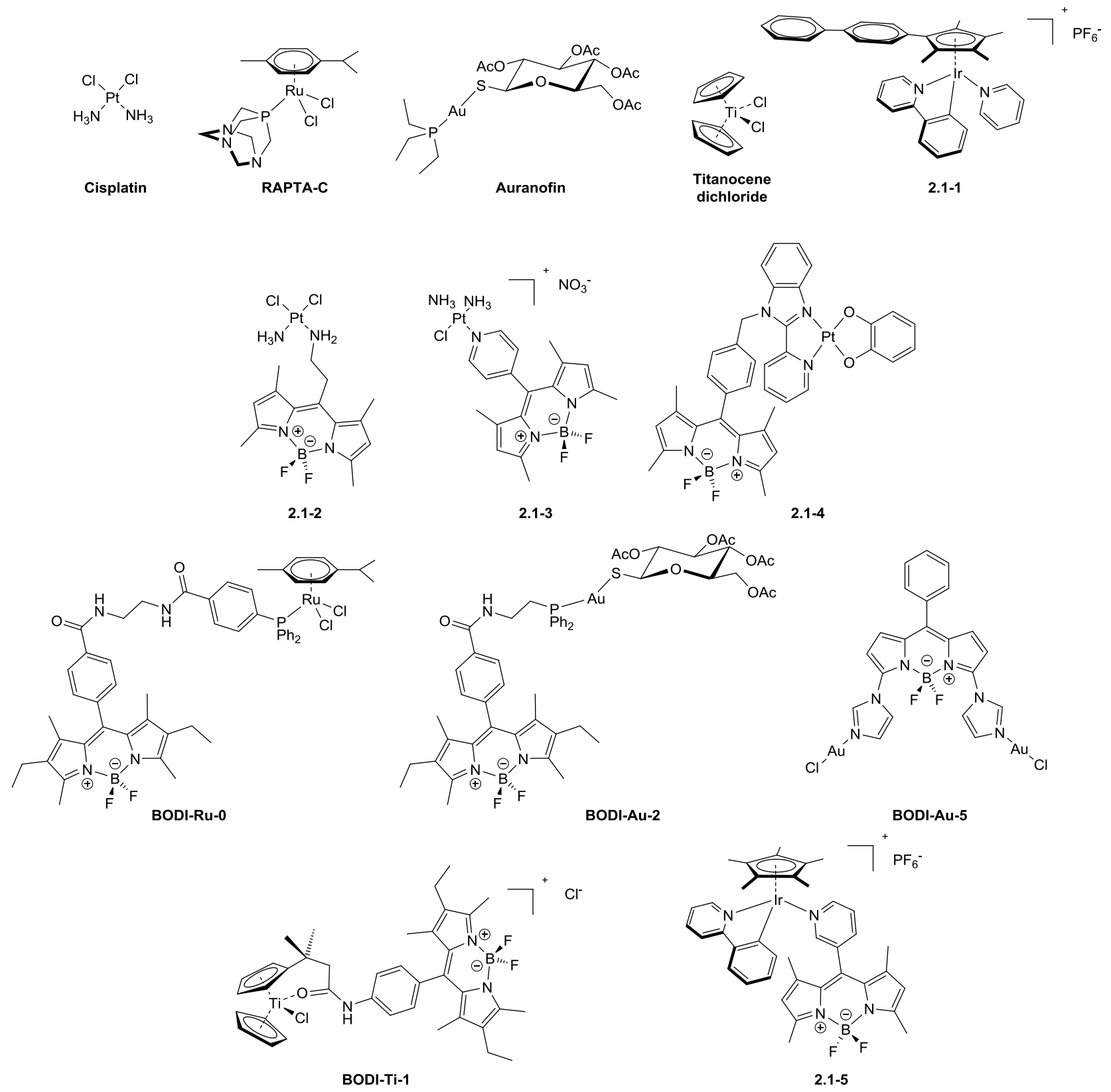

Figure 4. Structures of known anticancer metallodrugs and their BODIPY-labeled analogues

Auranofin is not reported to act by direct binding to DNA, but to induce apoptosis via a mitochondria-related pathway [52]. It was shown to be a highly potent and selective inhibitor of both cytosolic and mitochondrial isoforms of the selenoenzyme thioredoxin reductase (TrxR) [53]. The BODIPY-labeled analog of Auranofin (BODI-Au-2, Figure 4) was shown to accumulate in the cytosol and not in the nucleus by confocal microscopy [54]. This is in good agreement with the proposed mechanism of Auranofin. Moreover, upon incubation at $4^{\circ} \mathrm{C}$, uptake of BODI-Au-2 appeared to be reduced in both cell lines, suggesting the possible involvement of active transporters in its uptake mechanism [54]. In the same vein, following Trávníček's work - he reported on the antitumor and anti-inflammatory effect of some imidazole-gold complexes - [55-58], two homobimetallic gold(I) complexes using a BODIPY 
scaffold have been synthesized [59]. It was reported that BODI-Au-5 displays both strong antiproliferative and anti-inflammatory properties, along with a high in vitro brightness (tracking at submicromolar scale).

Titanocene dichloride (Figure 4) has demonstrated promising anticancer properties which lead it up to clinical trial where it failed due to a rather poor water stability $[60,61]$. Although the mechanism of action of titanocene dichloride has been extensively studied, a question remains under debate [62]. To investigate the mechanism of action of titanocene dichloride, a BODIPY moiety was grafted onto one of the cyclopentadienyl ligands (Cp) leading to complex BODI-Ti-1 (Figure 4) [63]. Using confocal microscopy, BODI-Ti-1 was located in the cytoplasm and not in the nucleus up to a concentration of 50 $\mu \mathrm{M}$ (Figure 5). This may suggest that a mitochondrial pathway rather than a DNA pathway might be responsible for its antiproliferative properties [62].
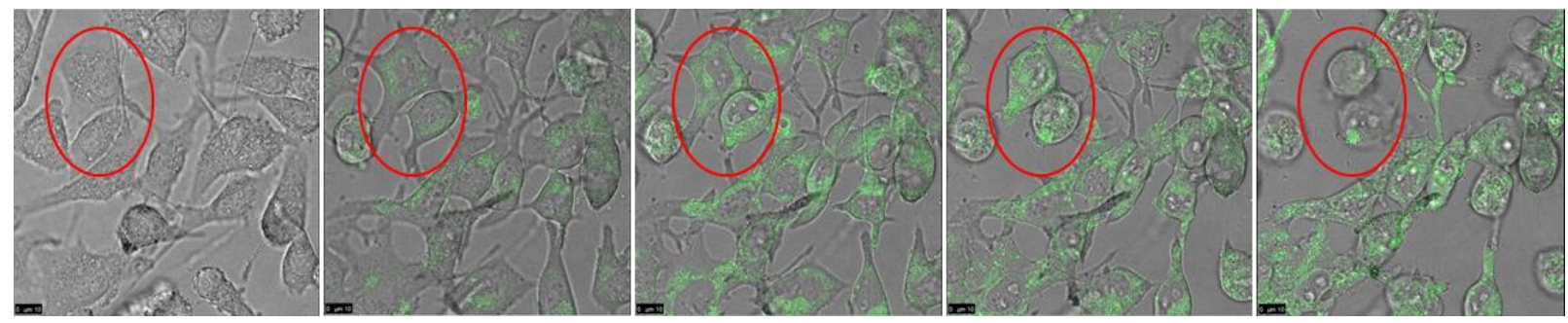

Figure 5. Real time imaging of BODI-Ti-1 in living B16F10 cells on 4 hours (the red circle highlights the death of two cells).

Cyclometallated iridium half-sandwich complexes (see complex 2.1-1 in Figure 4 as an example) have been studied thoroughly by Sadler and co-workers $[36,64]$. Their mode of action has been shown to involve induction of apoptosis via ROS production and mitochondrial membrane depolarization $[63,65]$. Compound 2.1-5 coupling the cyclometallated iridium half-sandwich scaffold to a BODIPY dye enabled the real-time observation of complex internalization while maintaining a rather good antiproliferative activity on several cancer cell lines [66]. The entry of complex 2.1-5 appeared to occur within the first seconds of incubation and the maximum uptake was reached after $90 \mathrm{~s}$ (Figure 6). Moreover, using epifluorescence microscopy, complex 2.1-5 was localized in the cytoplasm [61]. This is in fair agreement with data obtained from cellular fractionation and subsequent iridium quantification by ICP-MS with the non-labeled analogues of 2.1-5 [36]. Following incubation with complex 2.1-5, intracellular fluorescence was significantly reduced when incubation was carried out at $4^{\circ} \mathrm{C}$ with respect to $37^{\circ} \mathrm{C}$. This suggests the possible involvement of an active uptake mechanism [65].

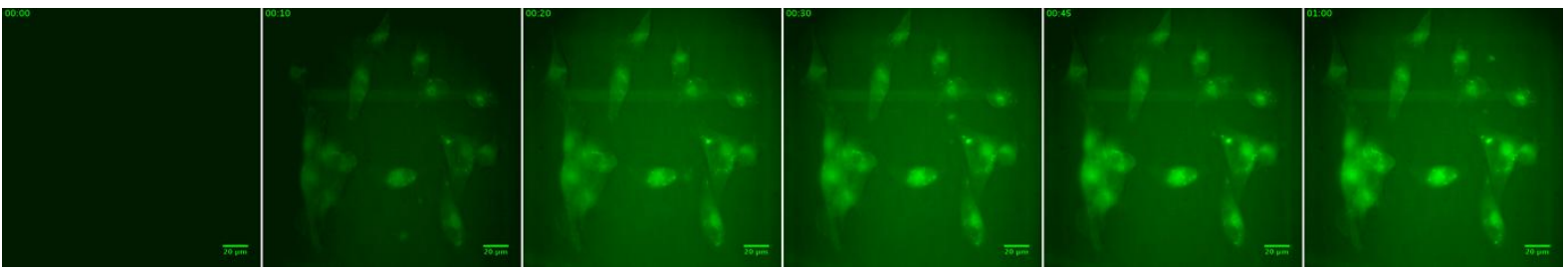

Figure 6. Fluorescence images of living MDA-MB-231 breast cancer cells exposed to $500 \mathrm{nM}$ of compound $2.1-5$ at $37^{\circ} \mathrm{C}$ at selected time points (from left to right: 0, 10, 20, 30, 45 and $60 \mathrm{~s}$ )

As mentioned above, fluorescent probes enable real time imaging of living cells. Indeed, it is possible to take pictures at different times and even to record a movie to track a therapeutic agent. This is of particular interest because it makes the tracking more reliable than performing the measure on 
different samples. Moreover, it is cost-effective because it decreases the number of samples to be studied and when imaging is performed on ex vivo or in vivo tissues it meets ethical requirements (to decrease the number of animals to sacrifice). However, to do so, the fluorescent probe needs to display a good resistance to photobleaching, which is the case of BODIPY derivatives contrary to most cyanines. Recently, some of us reported on two real time imaging studies enabling to see the theranostic agent enter the cells, accumulate in specific areas of the cells and trigger their death [63].

Optical imaging is a powerful qualitative technique, but quantification using fluorescence is tricky. Indeed, fluorescence depends of the solvent/medium where the fluorophore is located, thus, even with ratiometric probes it is difficult to properly quantify the amount of complex internalized. Thus, ICP-MS measurement is required for calibration [54].

All the previous examples highlighted a crucial point: the non-innocent character of the probe. Indeed, as soon as a fluorescent probe is tethered to a therapeutic agent, many of its properties change: size, lipophilicity, 3D-structure... Thus, it is important to keep in mind that grafting a probe to a known drug results in a new molecule, which may behave differently from the parent metal complex. In some cases, the introduction of the BODIPY can decrease the anti-proliferative properties of the complex $[51,67]$, and in other ones, it significantly increases them [63]. Moreover, it is very important to note that varying the fluorescent probe on the same metal complex can induce a different localization of the compound in cell. For example, when changing the probe on the gold phosphine metal complex, the resulting system accumulates even in the raft domains [68], in the nucleus [69], in the cytoplasm [51,70], or on the membrane [71] (Figure 7). That is why the probe has to be introduced at the beginning of the optimization process and will be a part of the final drug.

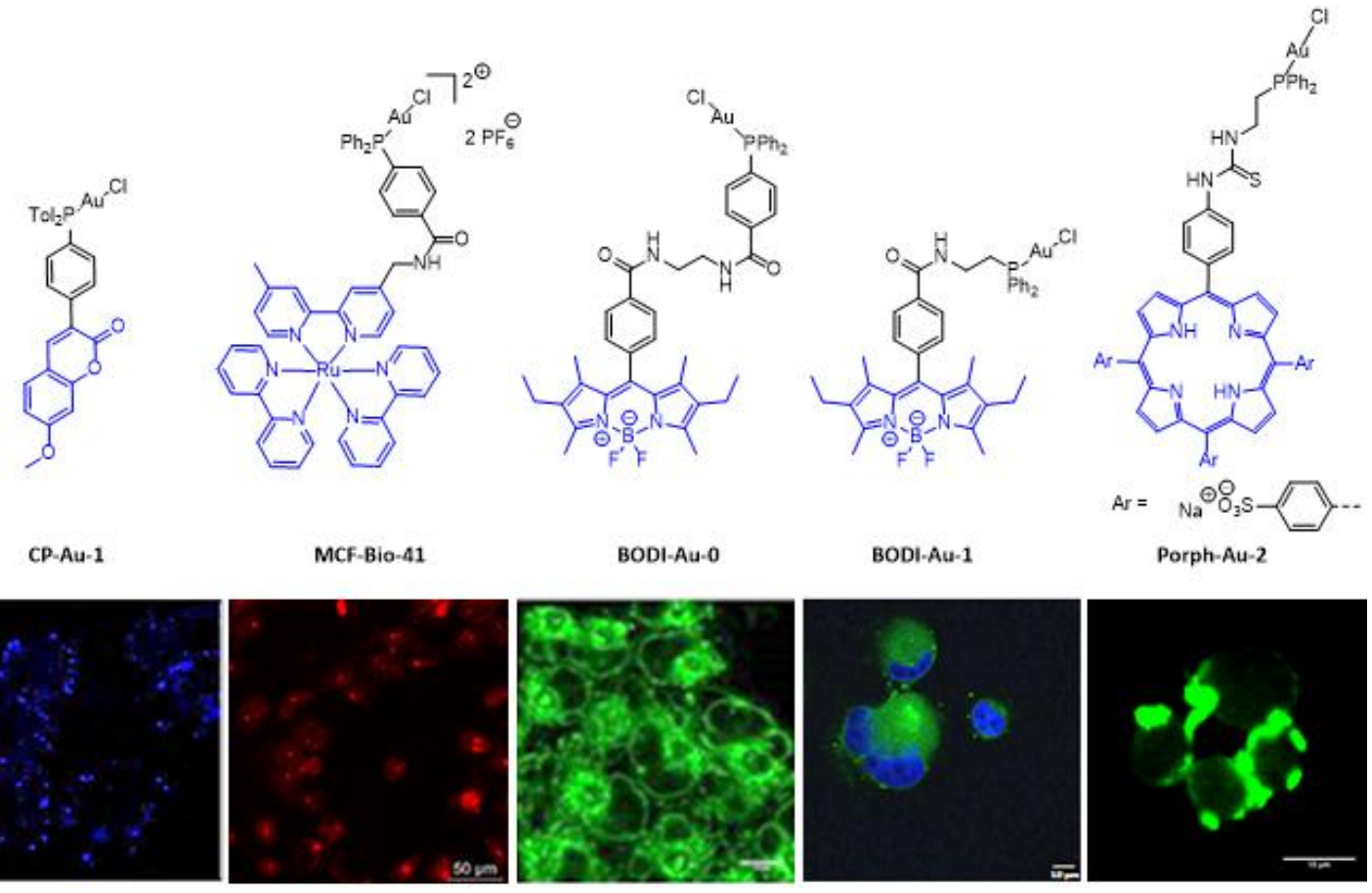

Figure 7. Impact of the luminescent probe on the localization of the theranostic agents in cancer cells. 


\subsection{Bio-conjugated theranostics}

In order to minimize the influence of the probe on the pharmacophore target and to increase the selectivity to cancer cells, some groups have decided to attach a bio-vector to BODIPY-labeled metal complexes, which will be recognized by receptors over-expressed by cancer cells. For example, conjugates BODI-Au-3 and BODI-Au-4 (Figure 8) present respectively a $\beta$-D-glucose moiety and a bombesin(7-14) fragment analogue for targeting of glucose transporters (Glut-1) and bombesin receptors (GRPR), respectively [54]. The complexity of building such conjugates comes from the possible interaction between the different parts of the molecule. Indeed, the presence of vectors on the BODIPYAu scaffold can induce a partial quench of the emission of the BODIPY. Reduction by $12 \%$ and $65 \%$ of the quantum yield for BODI-Au-3 and BODI-Au-4 respectively was measured with respect to the chlorido analogue in DMSO but no quench was observed in cells for BODI-Au-4. Nevertheless, the high brightness of BODIPYs allows such moderate quench. The presence of the BODIPY probe can also decrease the affinity of the vector for its receptor. Concerning BODI-Au-4, its affinity for the GRPR was found to be 5times lower than free native bombesin(1-14), which indicates the influence of the probe but which is comparable with the affinity of several bombesin derivatives, which were used successfully in imaging studies [72]. The uptake of both conjugates BODI-Au-3 and BODI-Au-4 by two cell lines overexpressing Glut-1 and GRPR receptors was shown by measurement of the intensity of fluorescence to be temperature-dependent. Indeed, when incubated at $4^{\circ} \mathrm{C}$, the cells treated with BODI-Au-3 and BODI-Au4 presented lower fluorescence suggesting the possible involvement of active transport mechanisms [54]. This study highlights another use of the presence of a fluorescent probe on a therapeutic agent, namely rapid evaluation of the efficiency of the vector.

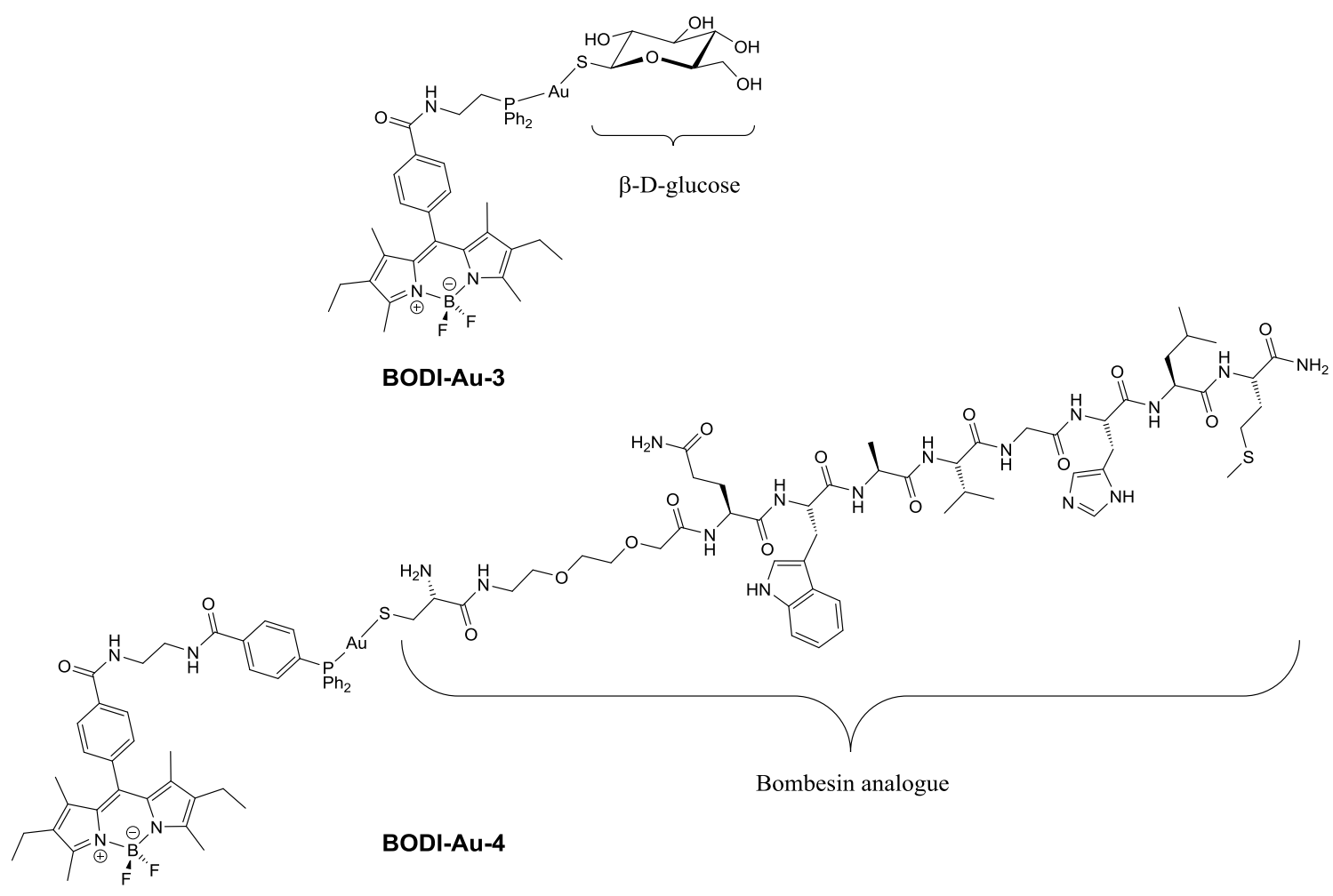

Figure 8. Structures of bioconjugated BODIPY-labeled metallodrugs. 


\subsection{Near IR BODIPY-metal complexes}

While fluorophores emitting in the UV-Vis region are suitable for in cellulo application, the high absorbance of tissues in this region limits their use in vivo. For in vivo application, the use of probes emitting in the near IR region, in which the tissue absorbance is low, is strongly advised [73]. Complex 2.3-1 (Figure 9) presents an extended bis-styryl BODIPY fluorophore emitting in the NIR region coupled to a cisplatin-like scaffold [74]. In cellulo, this compound was shown to accumulate in mitochondria just like its simpler "green-emitting" BODIPY analogue 2.1-3. Using intratumoral injections in mice bearing murine cervical cancer, complex 2.1-6 was visualized into the tumor up to 24 days after. Moreover, when injected subcutaneously to Chinese Kunming mice, complex 2.3-1 could reduce tumor weight with respect to the non-treated mice [74]. This suggests the possible application of this type of compounds as in vivo theranostics.

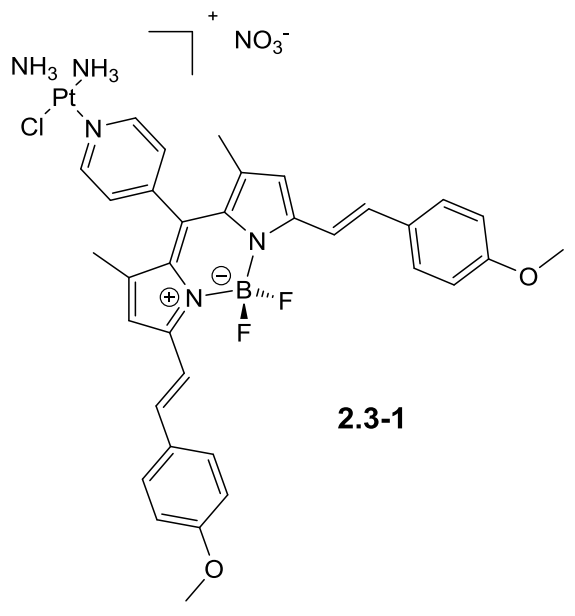

Figure 9. Structure of a NIR-BODIPY-labeled platinum complex.

\section{Metal-BODIPY bioconjugates for photodynamic therapy}

Photodynamic therapy (PDT) is a minimally invasive therapeutic modality that can selectively induce malignant cell death through the combined action of a photosensitizer (PS), light and dioxygen, none of which being individually toxic. Toxicity toward healthy tissues is minimized and resistance mechanisms do not occur in contrast to conventional chemotherapeutic procedures. During the PDT process, a highly reactive (and highly toxic) product named singlet oxygen ${ }^{1} \mathrm{O}_{2}$ is generated, eventually eliciting cell death by apoptosis or necrosis. Selectivity is ensured by the ability of the PS to localize in tumor tissue and precise delivery of light. Upon light excitation, the PS reaches an excited state that may further undergo intersystem crossing (ISC) to form a longer lifetime excited triplet state. Return to ground state may occur by radiative (phosphorescence) or non radiative processes. Alternatively, the energy of the triplet state may be transferred to molecular oxygen to afford ${ }^{1} \mathrm{O}_{2}$ according to the socalled Type II process which in turn generates ROS. As a general rule, a good PS should have a high extinction coefficient in the visible range, preferentially between 600 and $800 \mathrm{~nm}$ for optimal light penetration into tissues and be a long-lived excited triplet state emitter [75]. Within the last four years, some research teams became interested to design candidates for photodynamic therapy comprising a 
BODIPY moiety and a metal-containing entity following different approaches where both components played various roles alternatively.

BODIPY derivatives such as those depicted in Figure 1 are not suitable as photosensitizers but introduction of heavy atoms at suitable positions such as iodine at positions 2 and 6 of the indacene core was shown to greatly enhance ISC [76]. The diiodo-BODIPY derivative 3-1 (Figure 10) displays typical absorption / emission properties but low quantum yield and long excited triplet state lifetime (Table 1) [77]. Not surprisingly, this molecule behaved as a very good PS with singlet oxygen quantum yield $\Phi_{\Delta}$ of 0.79 [78]. Chakravarty and his team made use of this discovery to synthesize a diiodo BODIPY compound with a dipicolylamine copper(II) unit at the meso position (3-2, Figure 10) to increase its bioavailability. This compound is a good PS as shown by its high $\Phi_{\Delta}$ (Table 1), induces sc-DNA photocleavage and exhibits visible light activated cytotoxicity on MCF-7 breast cancer cell culture with a phototoxicity index (PI) of ca. 70 whereas the Cu complex itself is poorly active [79]. In a subsequent paper, the two chlorido ligands of 3-2 were replaced by curcumin acting as a bidentate 0,0 ligand both to target mitochondria and stabilize curcumin. Again 3-3 was 10 times more cytotoxic upon visible light irradiation [80].

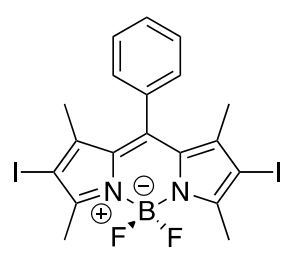

3-1

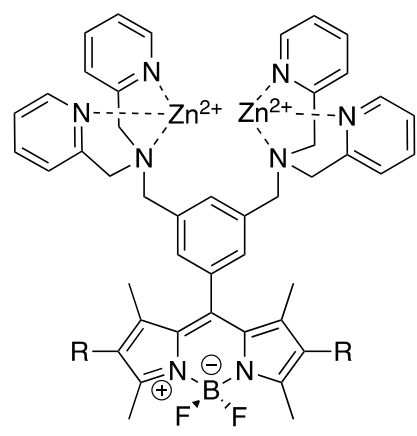

$\mathrm{R}=\mathrm{H}$, mSeek $\mathrm{R}=\mathrm{I}, \mathrm{mDestroy}$

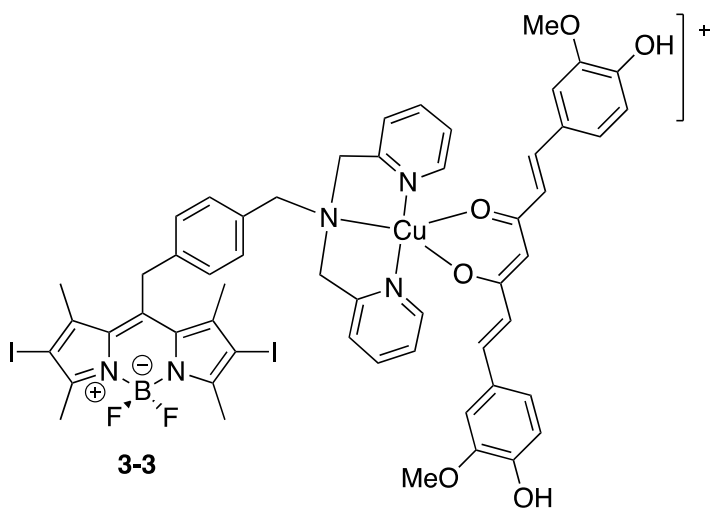

3-2

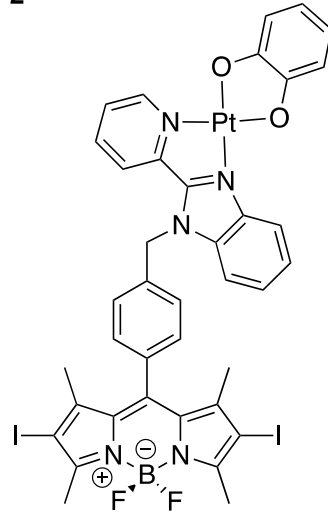

3-4
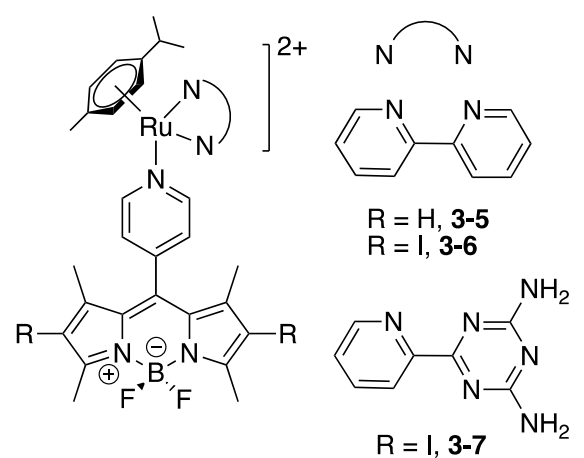

Figure 10. Diiodo-BODIPY-metal photosensitizers

Table 1. Photophysical properties of diiodo-BODIPY PDT / PDI agents

\begin{tabular}{lllllll}
\hline Compound & $\lambda_{\max }(\mathrm{nm})$ & $\lambda_{\mathrm{em}}(\mathrm{nm})$ & $\Phi^{\mathrm{a}}$ & $\Phi_{\Delta}{ }^{\mathrm{b}}$ & $\tau_{\mathrm{T}}(\mu \mathrm{s})^{\mathrm{c}}$ & Ref. \\
\hline $\mathbf{3 - 1}^{\mathrm{d}}$ & 529 & 548 & 0.029 & 0.79 & 85.2 & {$[78]$}
\end{tabular}




$\begin{array}{lllllll}\mathbf{3 - 2}^{\mathrm{e}} & 535 & 560 & 0.01 & 0.53 & \text { n.d. } & {[79]} \\ \mathbf{3 - 3}^{\mathrm{f}} & 432,535 & 512 & 0.01 & \text { n.d. } & \text { n.d. } & {[80]} \\ \text { mDestroy }^{\mathrm{g}} & 542 & -^{\mathrm{h}} & <0.01 & 0.57 & \text { n.d. } & {[81]} \\ \mathbf{3 - 4}^{\mathrm{i}} & 550 & -^{\mathrm{h}} & - & { }^{1} \mathrm{O}_{2} \text { produced but } & 2.62^{\mathrm{i}} & {[48]} \\ & & & & \text { not quantified } & & \\ \mathbf{3 - 5}^{\mathrm{j}} & 504 & 521 & 0.06 & 0.05 & - & {[82]} \\ \mathbf{3 - 6}^{\mathrm{j}} & 542 & 574 & 0.04 & 0.68 & 0.95 & {[82]} \\ \mathbf{3 - 7}^{\mathrm{j}} & 540 & 568 & 0.04 & 0.63 & 1.08 & {[82]} \\ \text { UiO-PDT }^{\mathrm{e}} & 524 & 563 & \text { n.d. } & { }^{1} \mathrm{O}_{2} \text { produced but } & \text { n.d. } & {[83]} \\ & & & & \text { not quantified } & & \end{array}$

${ }^{a}$ fluorescence quantum yield; ${ }^{b}$ singlet oxygen quantum yield; ${ }^{c}$ excited triplet state lifetime; ${ }^{d}$ in DCM; ${ }^{e}$ in DMF; ${ }^{f}$ in DMSO/PB $1: 1 ;^{\mathrm{g}}$ in PBS; ${ }^{\mathrm{h}}$ not fluorescent; ${ }^{\mathrm{i}}$ in DPBS/DMSO 9:1; ${ }^{\mathrm{j}}$ in MeCN

The same team reported the synthesis of the Pt(II) dyad 3-4 where the metal ion is coordinated by (2-pyridyl)benzylimidazole and catechol ligands (Figure 10). Cell fluorescence imaging with the non iodinated analog showed preferential accumulation in the mitochondria. Compound 3-4 displayed phototoxicity on Hacat cell culture after $4 \mathrm{~h}$ irradiation with visible light owing to ${ }^{1} \mathrm{O}_{2}$ production [48].

Half-sandwich ruthenium(II) (N,N) entities (N,N = bpy or 2-pyda-T) were appended to the meso position of BODIPY or diiodo BODIPY via coordination to pyridine substituent to afford 3-5, 3-6 and 3-7 (Figure 10). Interestingly, irradiation above $470 \mathrm{~nm}$ induced rapid dissociation of pyridyl-BODIPY ligand from 3-4, making it a potential photo-activated chemotherapy (PACT) agent operating in the visible range. The two diiodo-BODIPY-Ru dyads behave as PS since they are able to elicit ${ }^{1} \mathrm{O}_{2}$ generation, DNA cleavage and photocytotoxicity with PI of ca. 10 [82].

Three diiodo BODIPY molecules containing styryl entities at positions 3 and 5, pH and / or thiol cleavable linkers and ferrocenyl (Fc) groups as dark quenchers (3-8, 3-9 and 3-10, Figure 11) were designed so as to elicit the photosensitizing property upon response to single or dual stimulus. These compounds display characteristic absorption / emission features (662 / $684 \mathrm{~nm}$ ) and low quantum yield $(0.03-0.04)$ owing to photoinduced electron transfer $(\mathrm{PeT})$ quenching process induced by the $\mathrm{Fc}$ entities. Upon decrease of $\mathrm{pH}$ to 5 and / or presence of DTT, fluorescence in vitro and in cells as well as ${ }^{1} \mathrm{O}_{2}$ production were shown to increase as a result of ketal hydrolysis and / or S-S bond reduction. High photocytotoxicity of the diketal compounds was demonstrated on MCF-7 cell culture whereas photocytotoxicity of the disulfide compounds was stimulated by DTT [84]. 


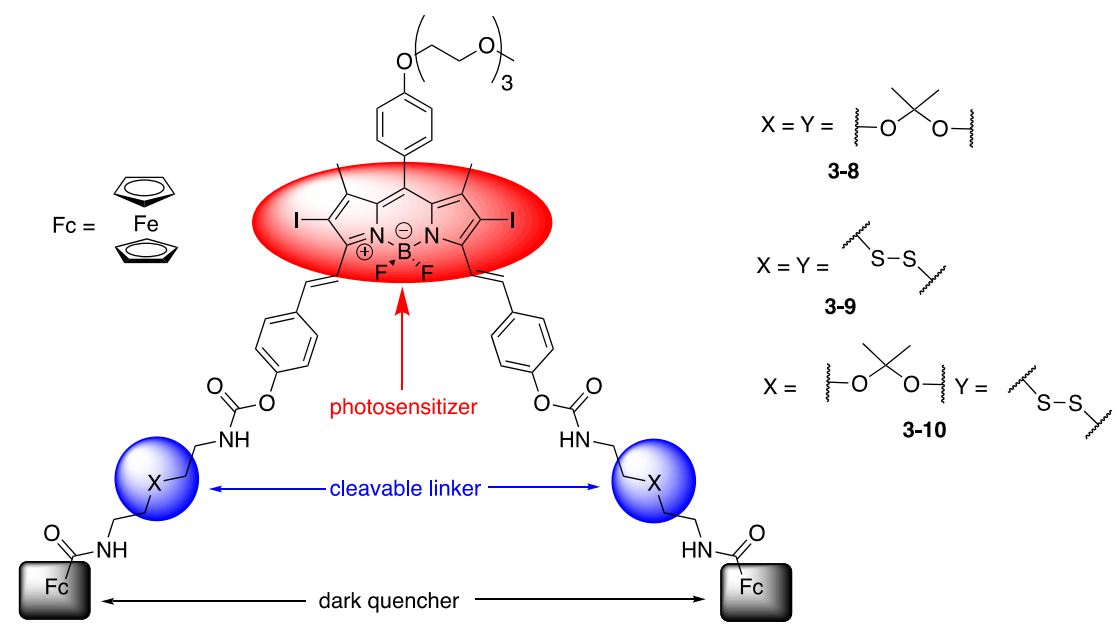

Figure 11. $\mathrm{pH}$ - and / or thiol-activable BODIPY photosensitizers

The PDT ability of the diiodo-BODIPY entity was introduced into nanoscale UiO-66 metal-organic framework (MOF) by solvent-assisted partial exchange of the 1,4-benzodicarboxylate struts linking the $\mathrm{Zr}_{6}$ clusters by a BODIPY carrying a carboxylic acid function (Figure 12). No change of the physical properties of the nanomaterial was noticed which displayed the absorption / emission properties of the BODIPY entity (Table 1). UiO-PDT was a moderate photoinducer of ${ }^{1} \mathrm{O}_{2}$ production and induced cell death upon irradiation with visible light. Cell uptake and localization of UiO-MOF was assessed by fluorescence microscopy [83]. In another paper, the authors suggest that the same nanomaterial could be potentially used as a contrast agent for computed tomography (CT) [85].

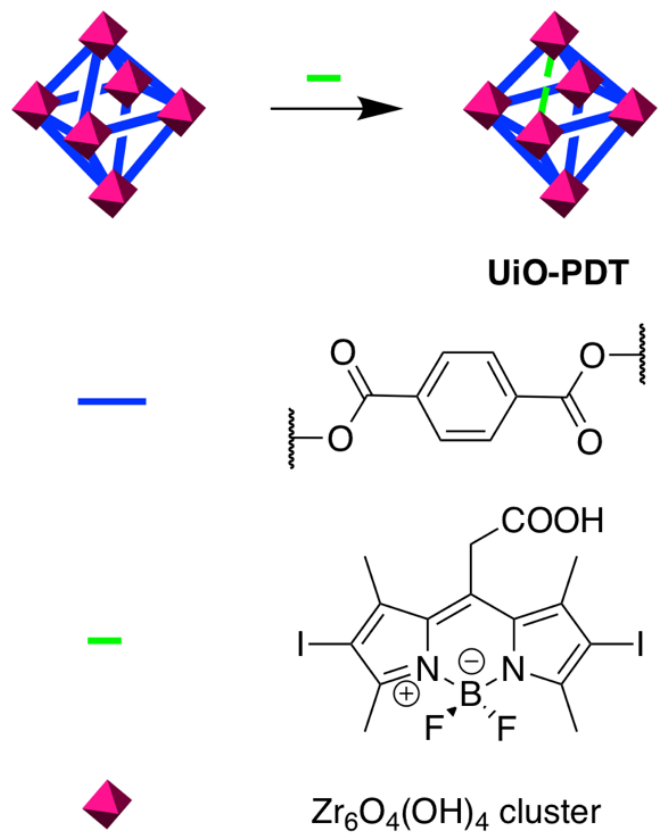

Figure 12. MOF-based BODIPY photosensitizer

Two dipicolylamine-Zn(II) entities targeting the bacterial surfaces were attached at the meso position of a diiodo BODIPY to give a highly positively charged dyad (mDestroy, Figure 10). The non iodinated analog (mSeek) was visualized within bacteria by fluorescence microscopy thanks to its intense 
emission ( $\Phi=0.53$ ) and mDestroy induced photodynamic inactivation (PDI) of Gram-positive bacterial strains and was inactive on mammalian cells. This selectivity was explained by the difference of surface charge between bacteria (anionic) and mammalian cells (nearly neutral) [81].

In the same line, an alkynyl $\mathrm{Au}(\mathrm{I})-\mathrm{PPh}_{3}$ entity was attached at position 5 of the BODIPY core to act as a heavy atom and enhance ISC (BODIPY-Au, Figure 13). Sharp decrease of the fluorescence was noticed along with high ${ }^{1} \mathrm{O}_{2}$ production upon irradiation at $525 \mathrm{~nm}$ (Table 2). Despite its low quantum yield, BODIPY-Au could be localized in cells by fluorescence microscopy. A543 cells loaded with as low as $2.5 \mathrm{nM}$ BODIPY-Au and irradiated for $5-30 \mathrm{~min}$ showed decreased viability compared to cells maintained in the dark $\left(\mathrm{IC}_{50}=0.16 \mu \mathrm{M}\right)$ [86].

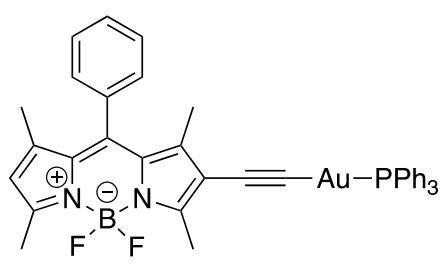

BODIPY-Au

Figure 13. BODIPY-Au(I) bioconjugate

The major drawback all these BODIPY derivatives is their common very poor emissive properties owing to efficient ISC, making them tricky to visualize in cells at low concentration. More generally, it is difficult to combine PDT and luminescence imaging abilities in the same material since the photophysical properties required for both functions are antagonist by essence. Some research groups became interested to associate cyclometalated iridium(III) entities known as excited triplet state emitters but weak absorbers and BODIPY acting as light-harvesting chromophore. For instance, Ortiz and coworkers appended a bis-cyclometalated $\operatorname{Ir}(\mathrm{III})$ unit at the meso position of BODIPY through coordination of acetylacetonate (acac) or dipyridophenazine (dppz) ligands (Ir-1 and Ir-3, Figure 14). Ir-1 displayed a modest quantum yield because of efficient ISC and a rather good singlet oxygen quantum yield $\Phi_{\Delta}$ (Table 2). Attachment of thiophene substituents at positions 2 and 6 of Ir-1 to afford Ir-2 shifted the absorption wavelength to ca. $600 \mathrm{~nm}$ with both good emission properties and good $\Phi_{\Delta}$ (Table 2). Ir-1 and Ir-2 were visualized in HeLa cells by fluorescence microscopy and exhibited significant cytotoxicity under green and red light irradiation, respectively [87]. 

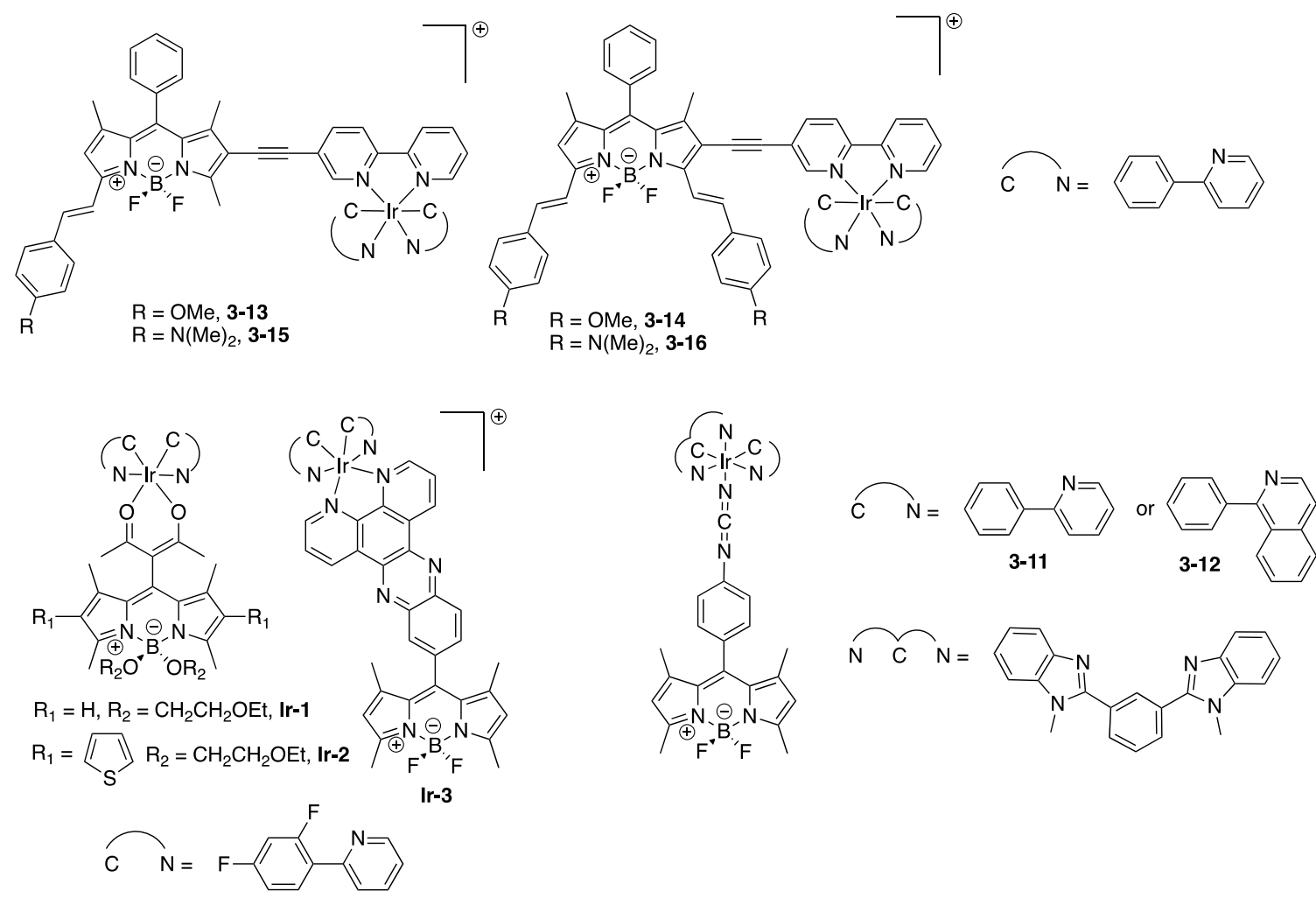

Figure 14. Cyclometalated iridium(III)-BODIPY conjugates

Two cyclometalated iridium(III) complexes comprising a NCN pincer ligand were anchored at the meso position of the BODIPY core by monodentate coordination to phenylcyanamide ligand (3-11 and 312, Figure 14). Both molecules exhibited low luminescence quantum yields but high $\Phi_{\Delta}$ when irradiated at $500 \mathrm{~nm}$ in MeCN (Table 2). As a result, these complexes were able to induce sc-DNA photocleavage and displayed high photocytotoxicity on HeLa cells $\left(\mathrm{IC}_{50}<1 \mu \mathrm{M}, \mathrm{PI}=113\right)$ while they were poorly active on the non tumorigenic cell line MRC-5 [88].

Table 2. Photophysical properties of Ir-and Au-based PDT agents measured in MeCN

\begin{tabular}{lllllll}
\hline Compound & $\lambda_{\max }(\mathrm{nm})$ & $\lambda_{\mathrm{em}}(\mathrm{nm})$ & $\Phi^{\mathrm{a}}$ & $\Phi_{\Delta}{ }^{\mathrm{b}}$ & $\tau_{\mathrm{T}}(\mu \mathrm{s})^{\mathrm{c}}$ & Ref. $^{\text {Ref }}$ \\
\hline 3-13 & 594,554 & 615 & 0.069 & 0.53 & 106.6 & {$[89]$} \\
3-14 & 647,596 & 673,609 & 0.1 & 0.81 & 156.5 & {$[89]$} \\
3-15 & 633 & 718 & 0.006 & 0.06 & 92.5 & {$[89]$} \\
3-16 & 710 & 787 & 0.002 & 0.02 & 31.4 & {$[89]$} \\
Ir-1 & 517 & 528 & 0.08 & 0.86 & n.d. & {$[87]$} \\
Ir-2 & 597 & 652 & 0.22 & 0.6 & n.d. & {$[87]$} \\
Ir-3 & 502 & 546 & 0.01 & $0.5^{\mathrm{d}}$ & n.d. & {$[87]$} \\
3-11 & 541 & 588 & 0.02 & 0.79 & 0.7 & {$[88]$} \\
3-12 & 526 & 598 & 0.02 & 0.92 & 0.73 & {$[88]$} \\
BODIPY-Au & 550 & 583 & 0.05 & 0.84 & n.d. & {$[86]$} \\
\hline
\end{tabular}


a fluorescence quantum yield; ${ }^{b}$ singlet oxygen quantum yield; ${ }^{c}$ excited triplet state lifetime; ${ }^{d}$ excitation at $370 \mathrm{~nm} ;{ }^{\mathrm{e}}$ in DCM

In a piece of work by Zhao and coworkers, the $\operatorname{Ir}(\mathrm{ppy})_{2}(\mathrm{bpy})$ entity was attached via $\pi$ conjugation with an alkynyl linker to the 6-position of the BODIPY core to maximize the heavy atom effect. One or two methoxy- or dimethylamino-styryl groups were introduced at positions 3 and 5 to shift the absorption / emission toward the NIR spectral region (3-13, 3-14, 3-15, 3-16, Figure 14). Of the series, the bismethoxy-styryl compound 3-14 displayed intense absorption in the red, good fluorescence quantum yield and high $\Phi_{\Delta}$ owing to its exceptionally long-lived excited triple state (Table 2). It was successfully imaged by CLSM and showed photocytotoxicity on two cell lines with modest PI (ca. 2) [89].

Photothermal therapy (PTT) is a dioxygen independent process where optical energy is converted into heat. This therapeutic modality presents the same benefits as PDT but can be employed in hypoxic environment found in solid tumors [90]. Qu, Chen and coworkers recently developed BODIPY$\mathrm{Mn}$ (II) nanomaterials as simultaneous contrast MRI and phototherapeutic agents. The nanoparticule (NP) agent was built up following the route schematized in Figure 15 where the first step relied on the selfassembly of a dimethoxystyryl BODIPY unit with a dipicolylamine-Mn(II) complex via hydrogen bond. The final 5-nm diameter Mn-DBA@BSA-FA NP displayed intense absorption at $640 \mathrm{~nm}$ but no emission. This nanomaterial was able to generate dioxygen at $\mathrm{pH} 5$ by photocatalytic oxidation of water and photothermal effect. Use of Mn-DBA@BSA-FA as tumor-selective MRI contrast agent as well as cytotoxic agent on HepG-2 cell culture and HepG-2 tumor bearing mice was demonstrated [91]. 

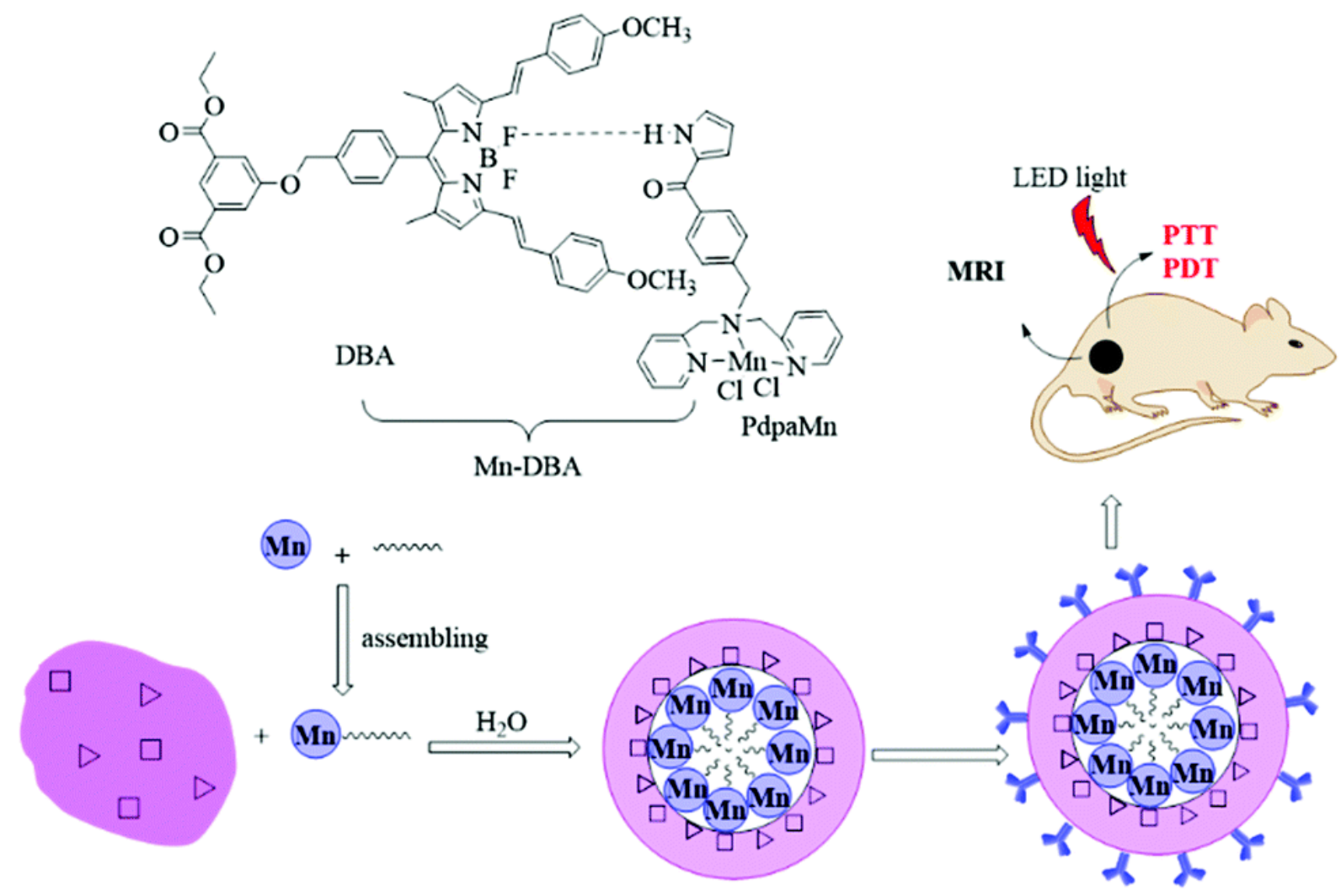

BSA

$$
\begin{aligned}
& \text { Mn = PdpaMn } \\
& \text { Figure 15. Mn-BODIPY based photothermal therapy agent. Reproduced from ref. [77] with permission from the Royal Society of } \\
& \text { Chemistry. }
\end{aligned}
$$

\section{Bimodal imaging probes}

\subsection{BODIPY based bimodal optical/PET or SPECT imaging probes}

Among the various approaches in medical imaging, there is an increasing interest in combining two different techniques providing an imaging approach that is complementary and highly translational [92,93]. Indeed, each molecular imaging technique has its own advantages and limitations, regarding spatial and temporal resolution, depth penetration, sensitivity and cost. In particular, combining fluorescence with nuclear imaging techniques (PET or SPECT) can be really advantageous due to their complementarity, both for preclinical and clinical use. PET and SPECT are powerful imaging techniques, that can provide critical in vivo information on the distribution of radiolabeled biomolecules. As mentioned before, fluorescence imaging has been demonstrated to be a powerful method for in vitro and ex vivo imaging, but also for intra-operative tumor detection in oncology [94]. The applications of such bimodality are numerous. For example, in the preclinical field, it can be used to co-validate a diagnosis or to bring complementary information, such as in vitro and ex vivo microscopy studies, in complement to in vivo PET or SPECT biodistribution study. Nevertheless, since both PET/SPECT and 
optical imaging have unique features for clinical applications, PET/fluorescence dual modality imaging might bring great benefit to the patients because the lesion could be located using non-invasive radioisotopic scans (diagnosis), and the optical probe would guide the surgeon to identify the detected lesions or smaller metastasis in intra-operative image-guided surgery (therapy). Additionally, another very important advantage of this combination is the comparable sensitivities of PET/SPECT and optical imaging, making it rational to prepare and administer optical agents in a manner that is similar to radiotracers. Concerning the nature of the radiotracer, the use of radiometals is of particular interest because of the wide range of nuclear properties (half-life, energy emission...) suitable for the labeling of various targeting biovectors. Despite all the advantages and the versatility of the BODIPY derivatives, the development of bimodal BODIPY-radiometal complexes is quite recent and poorly reported, maybe because of their lipophilic character, which requires some synthetic modifications of the dye for imaging applications, in particular in order to increase its water solubility. It is worth noting that in parallel to BODIPY-radiometal, BODIPY- ${ }^{18} \mathrm{~F}$ systems were also recently developed, taking advantage of the $\mathrm{F}$ atom on the fluorophore, which enables elegant radiofluorination on this position [95-101].

The first example of BODIPY-DOTA 4.1-1 bimodal agent was reported in 2010 (Figure 16) [102]. The synthetic strategy of this multimodal probe consisted in using a simple and versatile $p$ nitrophenylalanine (NPA) amino acid platform, on which could be successively introduced the DOTA chelating agent, the BODIPY, and an isothiocyanate functional group as a classical bioconjugatable handle. The corresponding $\mathrm{In}(\mathrm{III}), \mathrm{Ga}(\mathrm{III})$ and $\mathrm{Cu}(\mathrm{II})$ model complexes were also synthesized, in order to study the influence of the metal on the fluorescence of the BODIPY dye. Photophysical studies revealed that $\ln (\mathrm{III})$ and $\mathrm{Ga}$ (III) had almost no influence on the fluorescence of the BODIPY, whereas Cu(II) partially quenched this fluorescence, by a PeT mechanism, between the BODIPY and the metal, at the excited state.

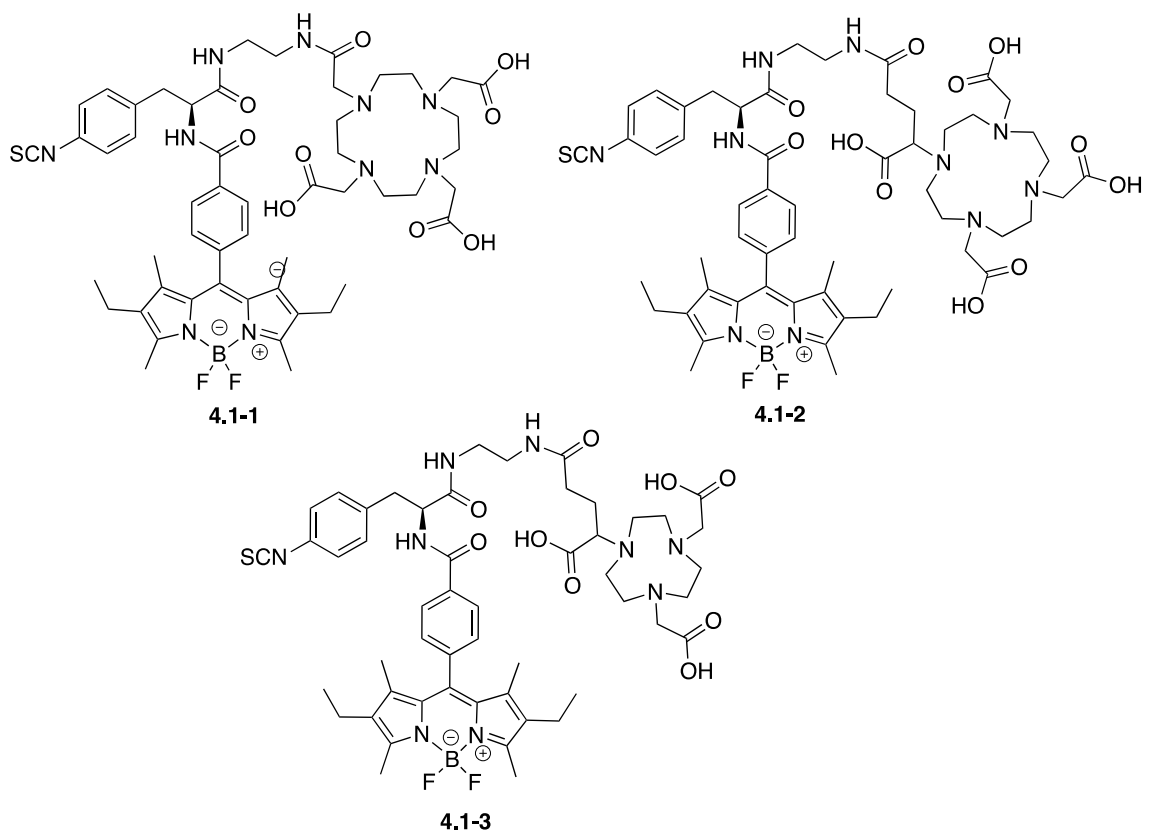

Figure 16. Structure of the BODIPY-NPA-polyazamacrocycles. 
Using the same synthetic approach enabled the same group to synthesize a family of different BODIPY-macrocycle bimodal probes. The difference lies in the nature of the macrocycle, which is a key parameter for optimal radiometalation. Indeed, 4.1-2 contains a DODAGA (GA stands for glutaric acid), which is a better chelating agent than DOTA, due to the four available coordinating carboxylic arms [103], while 4.1-3 - bearing a NODAGA macrocycle - is preferred for the complexation of ${ }^{68 / 67} \mathrm{Ga}$ or ${ }^{64} \mathrm{Cu}$ [104].

In another study, it was taken advantage of the isothiocyanate function of 4.1-1 to enable its bioconjugation to LPS (lipopolysaccharide) (Figure 17) [105]. After radiolabeling with [111 In]-indium, $\left[{ }^{111} \mathrm{In}\right]-20$ was injected into wild-type C57B16 mice, and in vivo biodistribution of the resulting radioconjugate was performed by SPECT-CT imaging. In a second step, ex vivo fluorescence microscopy studies enabled to visualize the accumulation of the tracer in the liver. In this study, $\left[{ }^{111} \mathrm{In}\right]-\mathbf{4 . 1 - 1}$ proved to be a relevant tool to support the fact that pro-inflammatory LPS can be transported from the periphery to the liver for detoxification.

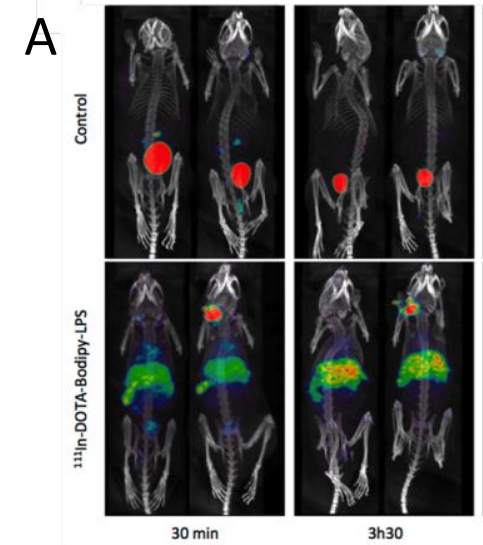

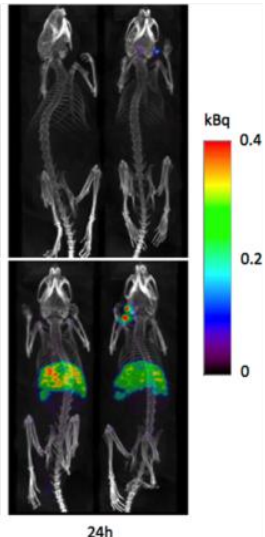

$24 \mathrm{~h}$

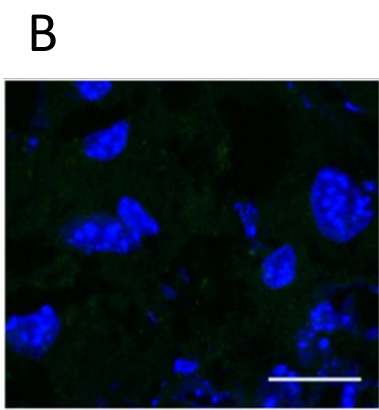

DAPI

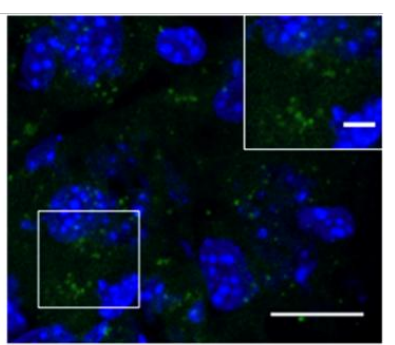

DAPI + BODIPY-DOTA-LPS

Figure 17. A. Biodistribution of radiolabeled LPS injected WT mice by SPECT-CT imaging. Control mice received a co-injection of ${ }^{111}$ In and DOTA-BODIPY-LPS without an incubation step. Residual ${ }^{111}$ In radiosignal can be detected in some mice at the injection site (jugular vein). B. Confocal microscopy images of liver cuts. Fluorescent signal in the liver of NaCl and DOTA-BODIPY-LPS injected WT mice

Compound 4.1-2 was bioconjugated to a cyclopeptide (Octreotide), which targets somatostatin receptors. In vivo studies were carried out and showed that bioconjugate 4.1-2-Oc was able to target SSTR2, despite a strong accumulation in the liver and the spleen, probably due to the lipophilic character of the bioconjugate [104]. This study confirmed that the biovector and/or the bimodal probes have to be chosen carefully because of the potential influence of the MOMIP (MOnomolecular Multimodal Imaging Probe) on the overall biodistribution properties of the resulting imaging agent

In a second step, the BODIPY-DOTA structure was optimized in order to be able to perform in vivo optical imaging. The objective of such modifications was to switch the absorption and emission of the dye toward the therapeutic window. To this aim, the conjugation on the previous BODIPY core was extended by performing Knoevenagel condensation (compound 4.1-4, Figure 18) [106]. Moreover, two additional DOTA macrocycles were added on the structure, which enabled to increase the hydrophilic character of the probe, as well as the radiolabeling yield. This bimodal probe was conjugated to 
Trastuzumab, a monoclonal antibody (mAb) used to treat HER2 positive breast cancer. A proof-ofconcept was achieved by preliminary optical in vivo studies on HER2 positive tumor-bearing mice. It enabled to visualize the imaging agent at the tumor site. The DOTA were also easily radiolabeled with ${ }^{111}$ In, resulting in a very stable radioconjugate. It revealed the potential of this new kind of bimodal probes for future bimodal imaging studies. However, up to now, no complete SPECT/PET/optical bimodal imaging study has been performed.
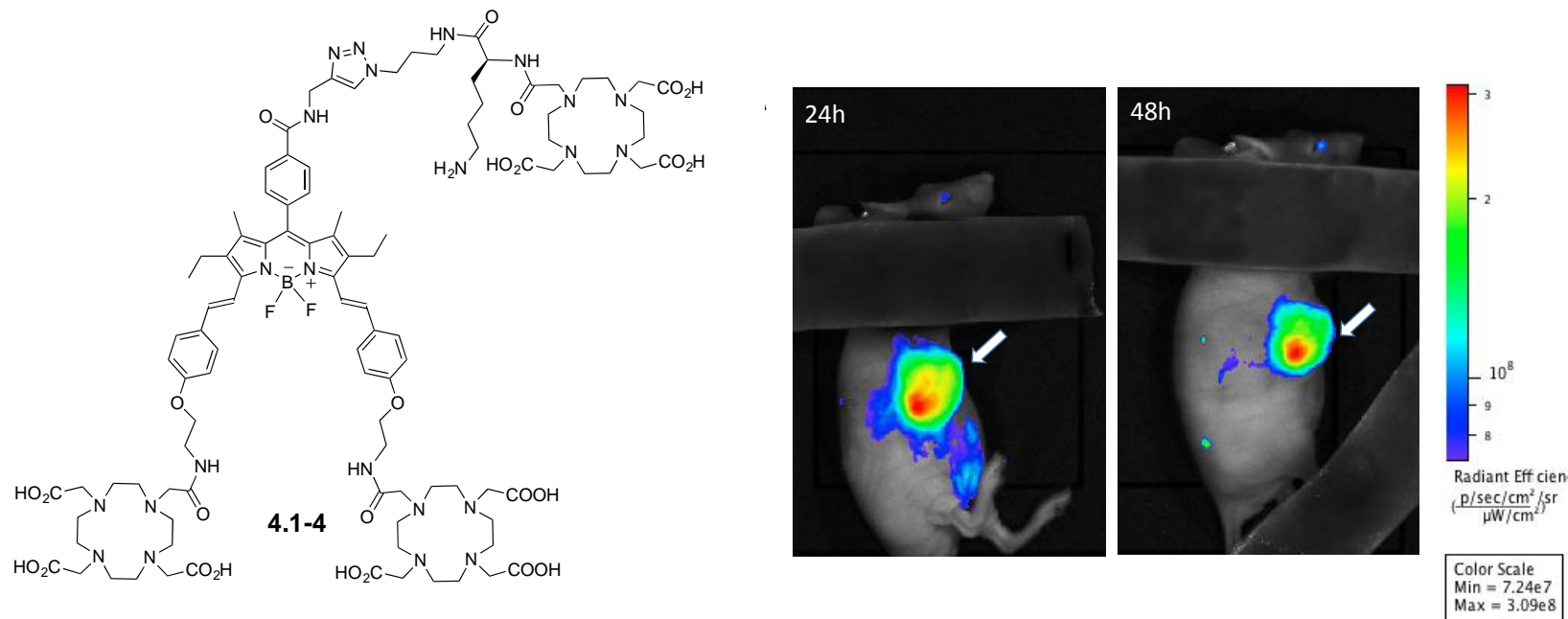

Figure 18. Structure of the BODIPY-distyryl-tris DOTA 4.1-4 (left) and direct comparison of NIR fluorescence images of a subcutaneous BT474 tumor-bearing mouse at 24 and $48 \mathrm{~h}$ post injection (Ex/Em: 660/710 nm) (right). The tumor site is indicated with a white arrow

In 2016, Boros, Weissleder and coll. reported a very original system for ${ }^{89} \mathrm{Zr}$ labeling, based on a BODIPY bearing a tetrazine as a bioorthogonal bioconjugatable handle, functionalized on the boron center with deferoxamine (DFO) for ${ }^{89} \mathrm{Zr}$ coordination [107]. The real advantage of this system is that the fluorescence of the BODIPY is quenched by the tetrazine (Tz), but is restored after bioconjugation to trans-cyclooctene (TCO) modified Trastuzumab mAb, therefore enabling to monitor and to control the ligation by fluorescence study. Radiolabeling with ${ }^{89} \mathrm{Zr}$ to form $\left[{ }^{89} \mathrm{Zr}\right.$ ]-DFO-BODIPY-Trastuzumab was found to be quantitative after incubation at room temperature for $1 \mathrm{~h}$. In vivo study on HER2 positive tumor bearing mice revealed a high accumulation of the ${ }^{89} \mathrm{Zr}$-DFO-BODIPY-Trastuzumab in the tumors as 
well as a high specificity, which was confirmed by ex vivo fluorescence microscopy studies (Figure 19).
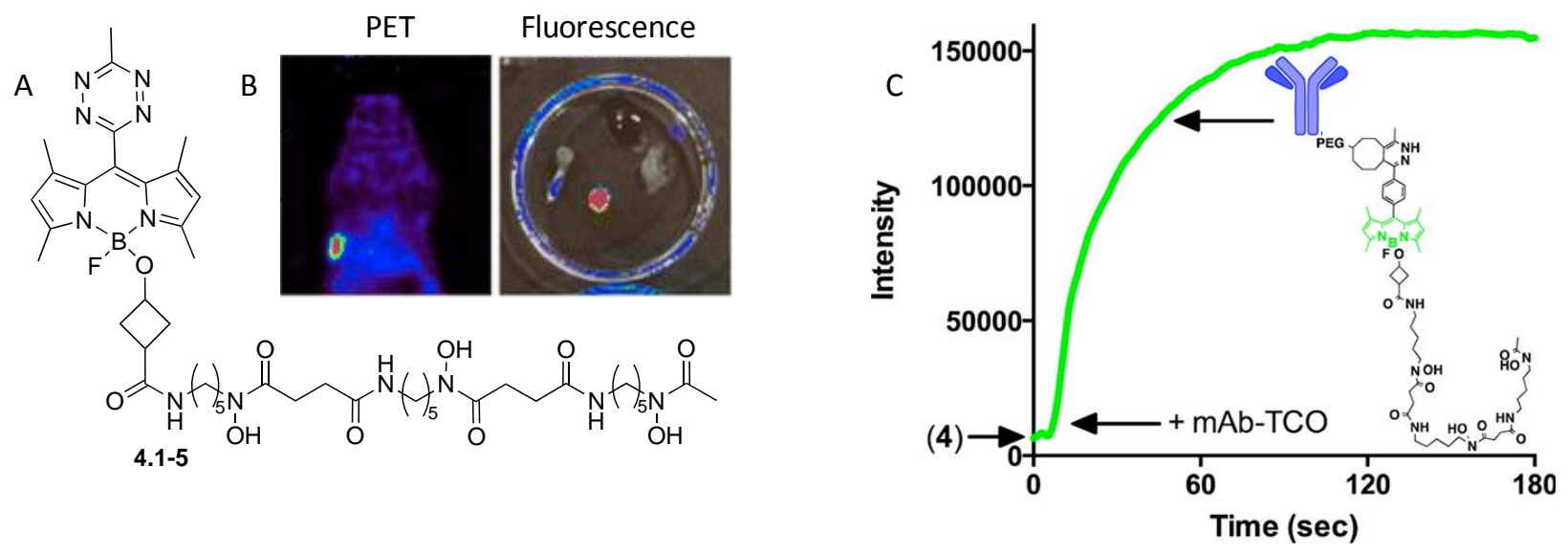

Figure 19. A. Structure of the Tz-BODIPY-DFO 4.1-5. B. Coronal image of mice with BT474 xenograft obtained with 89Zr-DFOBODIPY-Trastuzumab. C. Fluorescence turn-on observation during reaction between Trastuzumab-TCO and Tz-BODIPY-DFO to yield DFO-BODIPY-Trastuzumab. Reprinted figure with permission from reference [107]. Copyright (2017) American Chemical Society.

\subsection{BODIPY-based bimodal optical imaging / MRI agents}

Despite its excellent spatial resolution and depth penetration, Magnetic Resonance Imaging (MRI) is a poorly sensitive imaging technique. Thus, it is difficult to couple this modality to another one for designing MOMIP. The low sensitivity of MRI can be compensated by coupling the fluorophores to magnetic nanoparticules, resulting in bimodal imaging nanoparticules probes (nanoprobes). However, they are only few examples of BODIPY-based bimodal imaging nanoprobes to date.

Topel and coworkers reported the conjugation of a BODIPY derivative to superparamagnetic iron oxide nanoparticles (SPIONs), which were coated with PEI to generate surface amino groups (Figure 20). The resulting nanoprobe BDP-SPION displayed a blue-shifted broad absorption band centered at $362 \mathrm{~nm}$ and emission maximum at $506 \mathrm{~nm}$. This nanoprobe did not induce cytotoxicity on three different cell lines, exhibited good cellular uptake, and accumulated in the lipophilic regions of cells as shown by fluorescence imaging. The authors suggested that this nanoprobe could be used as MRI contrast agent because of its superparamagnetic properties [108]. Poly(lactic)acid NP impregnated with magnetite (as MRI probe) and labeled with an NIR BODIPY dye (as optical imaging probe) was produced and could be visualized by ex vivo MRI and confocal microscopy in the hippocampal brain tissue of epileptic rats [109].

Chen, Gao and coworkers designed a NP-based trimodal probe including dipicolylamine-Mn(II) complex as MRI probe and anticancer agent targeting HIF and LDH and BODIPY entity as optical probe $[91,110]$. This nanoprobe was obtained from the self-assembly of BDP-Mn-PEG depicted in Figure 20, by nanoprecipitation technique. Cell uptake of BDP-Mn-PEG was monitored by CLSM and this nanoprobe gave a good contrast in MRI. Interestingly, BDP-Mn-PEG presented anticancer properties on different cancer cell lines, and its mechanism of action was shown to occur via a ROS-mediated apoptotic pathway. Furthermore, in vivo studies revealed that the nanoprobe moderately inhibited tumor growth in mouse xenografts [110]. 


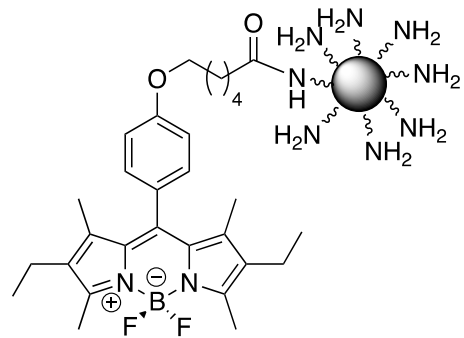

BDP-SPION

$362 / 506 \mathrm{~nm}$

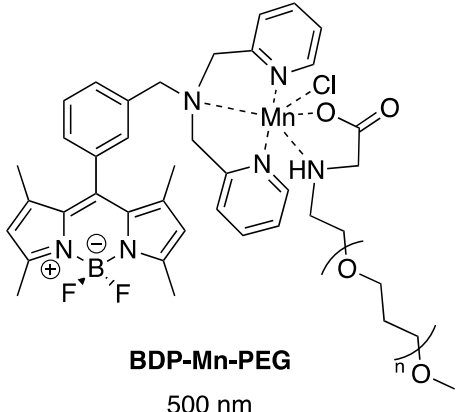

$500 \mathrm{~nm}$

Figure 20. Nanoprobes developed by Topel and coworkers left) and by Chen Gao and coworkers (right)

As mentioned above, it is difficult to make compatible optical imaging probe and MRI one in a single molecule. Nevertheless, if the toxicity of the resulting MOMIP is low and if the aim is not to target weakly expressed receptors, it is possible to combine optical imaging with MRI. Very few BODIPY-DOTAGd based bimodal probes have been developed to date (Figure 21).

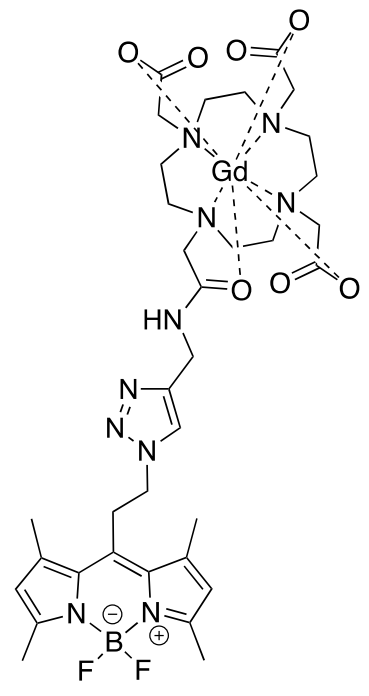

4.2-1

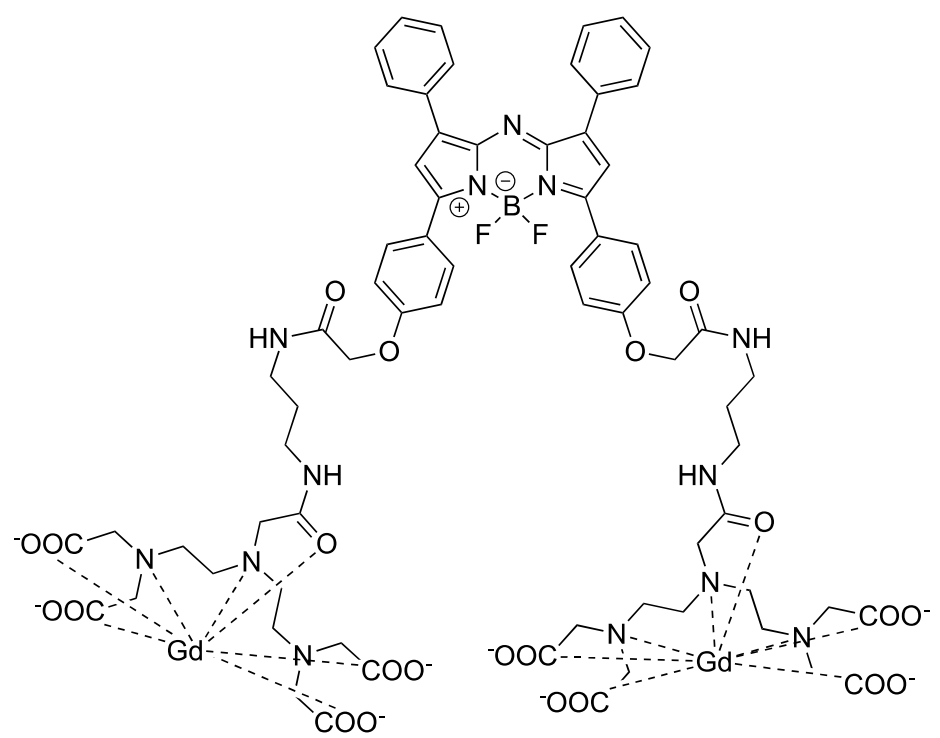

4.2-2

Figure 21. Structure of the BODIPY (25) and aza-BODIPY (26) - Gd bimodal agents.

In 2015, Vogt et al. developed the Gd-DOTA-BODIPY conjugate 4.2-1, that was synthesized by using click chemistry between a BODIPY dye and a DOTA moiety [111], resulting in a bimodal agent exhibiting a bright green fluorescence in aqueous solution and an excellent quantum yield. Additionally, the relaxivity of Gd-DOTA-BODIPY derivative measured at frequencies of 20 and $60 \mathrm{MHz}$ at $310 \mathrm{~K}$ was found to be 3.9 and $3.6 \mathrm{~s}^{-1} \cdot \mathrm{mM}^{-1}$ respectively. These values are close to previously reported values for $\mathrm{Gd}(\mathrm{III})$-DOTA complex, which gave values of 3.5 and $3.1 \mathrm{~s}^{-1} \cdot \mathrm{mM}^{-1}$ at 20 and $60 \mathrm{MHz}$ respectively.

In 2016, Hong et al developed the first aza-BODIPY based bimodal probe, with two Gd DTPA chelating units at the two arms of the fluorophore (4.2-2) [112]. This aza-BODIPY-based bimodal contrast 
agent showed a high fluorescence emission in the NIR range and an enhanced longitudinal relaxivity. The probe was delivered to phagocytic cells of the innate immune system, together with macrophages and dendritic cells (DCs), and presented high fluorescence and MR imaging without obvious cytotoxicity. Bone marrow- derived DCs were labeled with the bimodal agent and injected into the footpad of mice, and could be tracked in vivo by NIR optical imaging, in parallel to MRI, resulting in the first complete in vivo optical/nuclear bimodal study realized with BODIPY-metal -based bimodal probes (Figure 22).
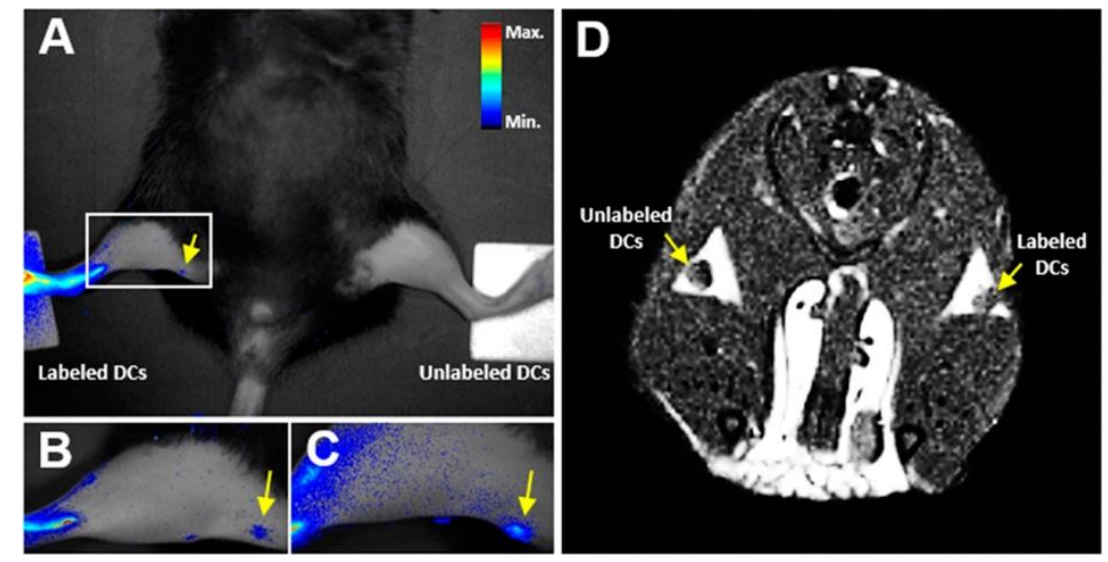

Figure 22. In vivo NIR optical and MRI tracking of 4.2-2-treated Bone-Marrow Derived Dendritic Cells (BMDCs) migration in draining Lymph Nodes (LNs) in mice. BMDCs treated with or without 4.2-2 were subcutaneously injected in both hind footpads at a density of $5 \times 10^{6}$ cells/mouse. NIR fluorescence $(A-C)$ and $M R(D)$ images were then acquired at $24 h(A, B$, and $D)$ and $48 h(C)$ after injection. NIR fluorescence images from whole body $(A)$ and magnified thigh $(B, C)$ were obtained by Maestro In-Vivo Imaging System (emission $=700 \mathrm{~nm}$, exposure time: $1000 \mathrm{~ms}$ ). In vivo $T_{1}$-weighted MR images were acquired by a $4.7 \mathrm{~T} \mathrm{MRI}$ system using MSME sequence. Arrows indicated the LNs. Reprinted figure with permission from reference [112]. Copyright (2017) American Chemical Society.

\section{Conclusion and perspectives}

To sum up, the association between highly fluorescent BODIPY entities and metal-containing entities results in multifunctional probes whose usefulness is clearly demonstrated in biology and medicine. By carefully designing the theranostic agent, useful information can be retrieved on uptake and distribution of metallodrugs and metallodrug candidates in cellular medium or even in whole animals. The BODIPY entity can be also employed as light harvester to enhance spin-orbit coupling and confer more efficient photosensitizing properties to cyclometalated iridium complexes. Bimodal imaging agents can be built up by adjoining a BODIPY entity to a PET / SPECT radiometal emitter. In a more sophisticated approach, a ligand is attached to the bimodal probe to guide it towards a specific receptor and improve its accumulation in target tissues. Less work has been done up to now on bimodal optical / MRI probes leaving room for future developments, especially in the nanoobjects area.

Given the versatility of BODIPY derivatives in terms of chemistry and photophysics, we can readily foresee other useful applications of metal-based BODIPY derivatives in medicinal chemistry. For instance, suitably designed BODIPY-based fluorescence switches may give clues regarding changes in the coordination sphere through ligand exchange / dissociation [113-115] and / or metal-centered redox processes [116] occurring in cellular environment. These probes should greatly help in deciphering the mechanism(s) of action of metallodrug candidates which might remain elusive otherwise. 


\section{Acknowledgement}

The LabEx MiChem part of French state funds managed by the ANR within the Investissements d'Avenir programme under reference ANR-11-IDEX-0004-02, the Conseil Régional de Bourgogne Franche-Comté (PARI II subprojects 2-p2 and 3-p2), the Ministère de l'Enseignement Supérieur et de la Recherche, the Centre National de la Recherche Scientifique (CNRS), and the French Research National Agency (ANR) via project JCJC "SPID" ANR-16-CE07-0020 are gratefully acknowledged for financial support. FrenchBIC is acknowledged for fruitful discussion.

\section{References}

[1] T. Kowada, H. Maeda, K. Kikuchi, BODIPY-based probes for the fluorescence imaging of biomolecules in living cells, Chem Soc Rev. 44 (2015) 4953-4972. doi:10.1039/C5CS00030K.

[2] A. Treibs, F.-H. Kreuzer, Difluorboryl-Komplexe von Di-und Tripyrrylmethenen, Eur. J. Org. Chem. 718 (1968) 208-223.

[3] F.J. Monsma, A.C. Barton, H. Chol Kang, D.L. Brassard, R.P. Haugland, D.R. Sibley, Characterization of novel fluorescent ligands with high affinity for D1 and D2 dopaminergic receptors, J. Neurochem. 52 (1989) 1641-1644.

[4] A. Loudet, K. Burgess, BODIPY Dyes and Their Derivatives: Syntheses and Spectroscopic Properties, Chem. Rev. 107 (2007) 4891-4932. doi:10.1021/cr078381n.

[5] G. Ulrich, R. Ziessel, A. Harriman, The Chemistry of Fluorescent Bodipy Dyes: Versatility Unsurpassed, Angew. Chem. Int. Ed. 47 (2008) 1184-1201. doi:10.1002/anie.200702070.

[6] N. Boens, B. Verbelen, W. Dehaen, Postfunctionalization of the BODIPY Core: Synthesis and Spectroscopy: Postfunctionalization of the BODIPY Core, Eur. J. Org. Chem. 2015 (2015) 6577-6595. doi:10.1002/ejoc.201500682.

[7] S.P. Singh, T. Gayathri, Evolution of BODIPY Dyes as Potential Sensitizers for Dye-Sensitized Solar Cells: Sensitizers for Dye-Sensitized Solar Cells, Eur. J. Org. Chem. 2014 (2014) 4689-4707. doi:10.1002/ejoc.201400093.

[8] B. Hinkeldey, A. Schmitt, G. Jung, Comparative Photostability Studies of BODIPY and Fluorescein Dyes by Using Fluorescence Correlation Spectroscopy, ChemPhysChem. 9 (2008) 20192027. doi:10.1002/cphc.200800299.

[9] G. Fan, L. Yang, Z. Chen, Water-soluble BODIPY and aza-BODIPY dyes: synthetic progress and applications, Front. Chem. Sci. Eng. 8 (2014) 405-417. doi:10.1007/s11705-014-1445-7.

[10] G. Sathyamoorthi, M.-L. Soong, T.W. Ross, J.H. Boyer, Fluorescent tricyclic $\beta$-azavinamidineBF2 complexes, Heteroat. Chem. 4 (1993) 603-608.

[11] Y. Ni, J. Wu, Far-red and near infrared BODIPY dyes: synthesis and applications for fluorescent pH probes and bio-imaging, Org. Biomol. Chem. 12 (2014) 3774. doi:10.1039/c3ob42554a.

[12] N. Boens, V. Leen, W. Dehaen, Fluorescent indicators based on BODIPY, Chem Soc Rev. 41

(2012) 1130-1172. doi:10.1039/C1CS15132K.

[13] L.A. Juárez, A. Barba-Bon, A.M. Costero, R. Martínez-Máñez, F. Sancenón, M. Parra, P. Gaviña, 
M.C. Terencio, M.J. Alcaraz, A Boron Dipyrromethene (BODIPY)-Based CuII-Bipyridine Complex for Highly Selective NO Detection, Chem. - Eur. J. 21 (2015) 15486-15490. doi:10.1002/chem.201502191.

[14] Y. Li, X. Wang, J. Yang, X. Xie, M. Li, J. Niu, L. Tong, B. Tang, Fluorescent Probe Based on Azobenzene-Cyclopalladium for the Selective Imaging of Endogenous Carbon Monoxide under Hypoxia Conditions, Anal. Chem. 88 (2016) 11154-11159. doi:10.1021/acs.analchem.6b03376.

[15] S. Medici, M. Peana, V.M. Nurchi, J.I. Lachowicz, G. Crisponi, M.A. Zoroddu, Noble metals in medicine: Latest advances, Coord. Chem. Rev. 284 (2015) 329-350. doi:10.1016/j.ccr.2014.08.002.

[16] K.D. Mjos, C. Orvig, Metallodrugs in Medicinal Inorganic Chemistry, Chem. Rev. 114 (2014) 4540-4563. doi:10.1021/cr400460s.

[17] N. Muhammad, Z. Guo, Metal-based anticancer chemotherapeutic agents, Curr. Opin. Chem. Biol. 19 (2014) 144-153. doi:10.1016/j.cbpa.2014.02.003.

[18] F. Trudu, F. Amato, P. Vaňhara, T. Pivetta, E.M. Peña-Méndez, J. Havel, Coordination compounds in cancer: Past, present and perspectives, J. Appl. Biomed. 13 (2015) 79-103. doi:10.1016/j.jab.2015.03.003.

[19] P. Zhang, P.J. Sadler, Advances in the design of organometallic anticancer complexes, J. Organomet. Chem. 839 (2017) 5-14. doi:10.1016/j.jorganchem.2017.03.038.

[20] M. Marloye, G. Berger, M. Gelbcke, F. Dufrasne, A survey of the mechanisms of action of anticancer transition metal complexes, Future Med. Chem. 8 (2016) 2263-2286. doi:10.4155/fmc-20160153.

[21] M. Fanelli, M. Formica, V. Fusi, L. Giorgi, M. Micheloni, P. Paoli, New trends in platinum and palladium complexes as antineoplastic agents, Coord. Chem. Rev. 310 (2016) 41-79.

doi:10.1016/j.ccr.2015.11.004.

[22] C. Roder, M.J. Thomson, Auranofin: Repurposing an Old Drug for a Golden New Age, Drugs RD. 15 (2015) 13-20. doi:10.1007/s40268-015-0083-y.

[23] A. Bergamo, G. Sava, Linking the future of anticancer metal-complexes to the therapy of tumour metastases, Chem. Soc. Rev. 44 (2015) 8818-8835. doi:10.1039/c5cs00134j.

[24] C.G. Hartinger, M.A. Jakupec, S. Zorbas-Seifried, M. Groessl, A. Egger, W. Berger, H. Zorbas, P.J. Dyson, B.K. Keppler, KP1019, A New Redox-Active Anticancer Agent - Preclinical Development and Results of a Clinical Phase I Study in Tumor Patients, Chem. Biodivers. 5 (2008) 2140-2155. doi:10.1002/cbdv.200890195.

[25] B.S. Murray, M.V. Babak, C.G. Hartinger, P.J. Dyson, The development of RAPTA compounds for the treatment of tumors, Coord. Chem. Rev. 306 (2016) 86-114. doi:10.1016/j.ccr.2015.06.014.

[26] C. Nardon, G. Boscutti, D. Fregona, Beyond Platinums: Gold Complexes as Anticancer Agents, Anticancer Res. 34 (2014) 487-492.

[27] T. Zou, C.T. Lum, C.-N. Lok, J.-J. Zhang, C.-M. Che, Chemical biology of anticancer gold((III)) and gold((I)) complexes, Chem. Soc. Rev. 44 (2015) 8786-8801. doi:10.1039/c5cs00132c.

[28] S.A. Patil, S.A. Patil, R. Patil, R.S. Keri, S. Budagumpi, G.R. Balakrishna, M. Tacke, Nheterocyclic carbene metal complexes as bio-organometallic antimicrobial and anticancer drugs, FUTURE 
Med. Chem. 7 (2015) 1305-1333. doi:10.4155/FMC.15.61.

[29] Y. Geldmacher, M. Oleszak, W.S. Sheldrick, Rhodium(III) and iridium(III) complexes as anticancer agents, Inorganica Chim. Acta. 393 (2012) 84-102. doi:10.1016/j.ica.2012.06.046.

[30] C.-H. Leung, H.-J. Zhong, D.S.-H. Chan, D.-L. Ma, Bioactive iridium and rhodium complexes as therapeutic agents, Coord. Chem. Rev. 257 (2013) 1764-1776. doi:10.1016/j.ccr.2013.01.034.

[31] M. Hanif, M.V. Babak, C.G. Hartinger, Development of anticancer agents: wizardry with osmium, Drug Discov. Today. 19 (2014) 1640-1648. doi:10.1016/j.drudis.2014.06.016.

[32] S.S. Braga, A.M.S. Silva, A New Age for Iron: Antitumoral Ferrocenes, Organometallics. 32 (2013) 5626-5639. doi:10.1021/om400446y.

[33] G. Jaouen, A. Vessières, S. Top, Ferrocifen type anti cancer drugs, Chem. Soc. Rev. 44 (2015) 8802-8817. doi:10.1039/C5CS00486A.

[34] M. Wenzel, B. Bertrand, M.-J. Eymin, V. Comte, J.A. Harvey, P. Richard, M. Groessl, O. Zava, H. Amrouche, P.D. Harvey, P. Le Gendre, M. Picquet, A. Casini, Multinuclear Cytotoxic Metallodrugs: Physicochemical Characterization and Biological Properties of Novel Heteronuclear Gold-Titanium Complexes, Inorg. Chem. 50 (2011) 9472-9480. doi:10.1021/ic201155y.

[35] M. Wenzel, E. Bigaeva, P. Richard, P. Le Gendre, M. Picquet, A. Casini, E. Bodio, New heteronuclear gold(I)-platinum(II) complexes with cytotoxic properties: Are two metals better than one?, J. Inorg. Biochem. 141 (2014) 10-16. doi:10.1016/j.jinorgbio.2014.07.011.

[36] A.J. Millett, A. Habtemariam, I. Romero-Canelón, G.J. Clarkson, P.J. Sadler, Contrasting Anticancer Activity of Half-Sandwich Iridium(III) Complexes Bearing Functionally Diverse 2- Phenylpyridine Ligands, Organometallics. 34 (2015) 2683-2694. doi:10.1021/acs.organomet.5b00097.

[37] B. Bertrand, J. Fernandez-Cestau, J. Angulo, M.M.D. Cominetti, Z.A.E. Waller, M. Searcey, M.A. O’Connell, M. Bochmann, Cytotoxicity of Pyrazine-Based Cyclometalated $\left(\mathrm{C}^{\wedge} \mathrm{N}(\mathrm{pz})^{\wedge} \mathrm{C}\right) \mathrm{Au}(\mathrm{III})$ Carbene Complexes: Impact of the Nature of the Ancillary Ligand on the Biological Properties, Inorg. Chem. 56 (2017) 5728-5740. doi:10.1021/acs.inorgchem.7b00339.

[38] C. Schmidt, B. Karge, R. Misgeld, A. Prokop, R. Franke, M. Brönstrup, I. Ott, Gold(I) NHC Complexes: Antiproliferative Activity, Cellular Uptake, Inhibition of Mammalian and Bacterial Thioredoxin Reductases, and Gram-Positive Directed Antibacterial Effects, Chem. - Eur. J. 23 (2017) 1869-1880. doi:10.1002/chem.201604512.

[39] B. Rosenberg, L. VanCamp, J.E. Trosko, V.H. Mansour, Platinum compounds: a new class of potent antitumour agents, Nature. 222 (1969) 385-386.

[40] M.D. Hall, C.T. Dillon, M. Zhang, P. Beale, Z. Cai, B. Lai, A.P.J. Stampfl, T.W. Hambley, The cellular distribution and oxidation state of platinum(II) and platinum(IV) antitumour complexes in cancer cells, JBIC J. Biol. Inorg. Chem. 8 (2003) 726-732. doi:10.1007/s00775-003-0471-6.

[41] M. Groessl, O. Zava, P.J. Dyson, Cellular uptake and subcellular distribution of ruthenium-based metallodrugs under clinical investigation versus cisplatin, Metallomics. 3 (2011) 591-599. doi:10.1039/C0MT00101E.

[42] J.C. Jagodinsky, A. Sulima, Y. Cao, J.E. Poprawski, B.N. Blackman, J.R. Lloyd, R.E. Swenson, M.M. Gottesman, M.D. Hall, Evaluation of fluorophore-tethered platinum complexes to monitor the fate 
of cisplatin analogs, JBIC J. Biol. Inorg. Chem. 20 (2015) 1081-1095. doi:10.1007/s00775-015-1290-2.

[43] G. Gupta, A. Das, N.B. Ghate, T. Kim, J.Y. Ryu, J. Lee, N. Mandal, C.Y. Lee, Novel BODIPYbased $\mathrm{Ru}(\mathrm{II})$ and $\operatorname{Ir}(\mathrm{III})$ metalla-rectangles: cellular localization of compounds and their antiproliferative activities, Chem. Commun. 52 (2016) 4274-4277. doi:10.1039/C6CC00046K.

[44] G. Gupta, A. Das, K.C. Park, A. Tron, H. Kim, J. Mun, N. Mandal, K.-W. Chi, C.Y. Lee, SelfAssembled Novel BODIPY-Based Palladium Supramolecules and Their Cellular Localization, Inorg. Chem. 56 (2017) 4615-4621. doi:10.1021/acs.inorgchem.7b00260.

[45] G. Gupta, A. Das, S. Panja, J.Y. Ryu, J. Lee, N. Mandal, C.Y. Lee, Self-Assembly of Novel Thiophene-Based BODIPY RuII Rectangles: Potential Antiproliferative Agents Selective Against Cancer Cells, Chem. - Eur. J. 23 (2017) 17199-17203. doi:10.1002/chem.201704368.

[46] M.A. Miller, B. Askevold, K.S. Yang, R.H. Kohler, R. Weissleder, Platinum Compounds for High-Resolution In Vivo Cancer Imaging, ChemMedChem. 9 (2014) 1131-1135. doi:10.1002/cmdc.201300502.

[47] T. Sun, X. Guan, M. Zheng, X. Jing, Z. Xie, Mitochondria-Localized Fluorescent BODIPYPlatinum Conjugate, ACS Med. Chem. Lett. 6 (2015) 430-433. doi:10.1021/acsmedchemlett.5b00041.

[48] K. Mitra, S. Gautam, P. Kondaiah, A.R. Chakravarty, BODIPY-Appended 2-(2Pyridyl)benzimidazole Platinum(II) Catecholates for Mitochondria-Targeted Photocytotoxicity, ChemMedChem. 11 (2016) 1956-1967. doi:10.1002/cmdc.201600320.

[49] G.V. Kalayda, G. Zhang, T. Abraham, H.J. Tanke, J. Reedijk, Application of Fluorescence Microscopy for Investigation of Cellular Distribution of Dinuclear Platinum Anticancer Drugs, J. Med. Chem. 48 (2005) 5191-5202. doi:10.1021/jm050216h.

[50] A. Bergamo, A. Masi, P.J. Dyson, G. Sava, Modulation of the metastatic progression of breast cancer with an organometallic ruthenium compound, Int. J. Oncol. 33 (2008) 1281-1289.

[51] S. Tasan, O. Zava, B. Bertrand, C. Bernhard, C. Goze, M. Picquet, P. Le Gendre, P. Harvey, F. Denat, A. Casini, E. Bodio, BODIPY-phosphane as a versatile tool for easy access to new metal-based theranostics, Dalton Trans. 42 (2013) 6102-6109. doi:10.1039/C2DT32055J.

[52] T.M. Simon, D.H. Kunishima, G.J. Vibert, A. Lorber, Inhibitory effects of a new oral gold compound on HeLa cells, Cancer. 44 (1979) 1965.

[53] M.P. Rigobello, L. Messori, G. Marcon, M. Agostina Cinellu, M. Bragadin, A. Folda, G. Scutari, A. Bindoli, Gold complexes inhibit mitochondrial thioredoxin reductase: consequences on mitochondrial functions, J. Inorg. Biochem. 98 (2004) 1634-1641. doi:10.1016/j.jinorgbio.2004.04.020.

[54] P.-E. Doulain, R. Decréau, C. Racoeur, V. Goncalves, L. Dubrez, A. Bettaieb, P.L. Gendre, F. Denat, C. Paul, C. Goze, E. Bodio, Towards the elaboration of new gold-based optical theranostics, Dalton Trans. 44 (2015) 4874-4883. doi:10.1039/C4DT02977A.

[55] Z. Trávníček, P. Štarha, J. Vančo, T. Šilha, J. Hošek, P. Suchý, G. Pražanová, Anti-inflammatory Active Gold(I) Complexes Involving 6-Substituted-Purine Derivatives, J. Med. Chem. 55 (2012) 45684579. doi:10.1021/jm201416p.

[56] J. Hošek, J. Vančo, P. Štarha, L. Paráková, Z. Trávníček, Effect of 2-Chloro-Substitution of Adenine Moiety in Mixed-Ligand Gold(I) Triphenylphosphine Complexes on Anti-Inflammatory 
Activity: The Discrepancy between the In Vivo and In Vitro Models, PLOS ONE. 8 (2013) e82441. doi:10.1371/journal.pone.0082441.

[57] J. Vančo, J. Gáliková, J. Hošek, Z. Dvořák, L. Paráková, Z. Trávníček, Gold(I) Complexes of 9Deazahypoxanthine as Selective Antitumor and Anti-Inflammatory Agents, PLOS ONE. 9 (2014) e109901. doi:10.1371/journal.pone.0109901.

[58] R. Křikavová, J. Hošek, P. Suchý Jr., J. Vančo, Z. Trávníček, Diverse in vitro and in vivo antiinflammatory effects of trichlorido-gold(III) complexes with N6-benzyladenine derivatives, J. Inorg. Biochem. 134 (2014) 92-99. doi:10.1016/j.jinorgbio.2014.02.002.

[59] A. Trommenschlager, F. Chotard, B. Bertrand, S. Amor, L. Dondaine, M. Picquet, P. Richard, A. Bettaïeb, P.L. Gendre, C. Paul, C. Goze, E. Bodio, Gold(I)-BODIPY-imidazole bimetallic complexes as new potential anti-inflammatory and anticancer trackable agents, Dalton Trans. (2017). doi:10.1039/C7DT01377A.

[60] G. Lümmen, H. Sperling, H. Luboldt, T. Otto, H. Rübben, Phase II trial of titanocene dichloride in advanced renal-cell carcinoma, Cancer Chemother. Pharmacol. 42 (1998) 415-417.

doi:10.1007/s002800050838.

[61] J.H. Murray, M.M. Harding, Organometallic Anticancer Agents: The Effect of the Central Metal and Halide Ligands on the Interaction of Metallocene Dihalides Cp2MX2 with Nucleic Acid Constituents, J. Med. Chem. 37 (1994) 1936-1941. doi:10.1021/jm00039a005.

[62] M. Cini, T.D. Bradshaw, S. Woodward, Using titanium complexes to defeat cancer: the view from the shoulders of titans, Chem. Soc. Rev. 46 (2017) 1040-1051. doi:10.1039/c6cs00860g.

[63] O. Florès, A. Trommenschlager, S. Amor, F. Marques, F. Silva, L. Gano, F. Denat, M.P.C. Campello, C. Goze, E. Bodio, P.L. Gendre, In vitro and in vivo trackable titanocene-based complexes using optical imaging or SPECT, Dalton Trans. (2017). doi:10.1039/C7DT01981E.

[64] Z. Liu, I. Romero-Canelón, B. Qamar, J.M. Hearn, A. Habtemariam, N.P.E. Barry, A.M. Pizarro, G.J. Clarkson, P.J. Sadler, The Potent Oxidant Anticancer Activity of Organoiridium Catalysts, Angew. Chem. 126 (2014) 4022-4027. doi:10.1002/ange.201311161.

[65] J.M. Hearn, I. Romero-Canelón, B. Qamar, Z. Liu, I. Hands-Portman, P.J. Sadler, Organometallic iridium(III) anticancer complexes with new mechanisms of action: NCI-60 screening, mitochondrial targeting, and apoptosis, ACS Chem. Biol. Volume 8 (2013) 1335-1343.

[66] J. Zimbron, K. Passador, B. Gatin-Fraudet, C.-M. Bachelet, D. Plazuk, L.-M. Chamoreau, C. Botuha, S. Thorimbert, M. Salmain, Synthesis, Photophysical Properties, and Living Cell Imaging of Theranostic Half-Sandwich Iridium-4,4-Difluoro-4- bora- 3a,4a- diaza- s- indacene (BODIPY) Dyads, Organometallics. (2017). doi:10.1021/acs.organomet.7b00250.

[67] P.-E. Doulain, R. Decréau, C. Racoeur, V. Goncalves, L. Dubrez, A. Bettaieb, P.L. Gendre, F. Denat, C. Paul, C. Goze, E. Bodio, Towards the elaboration of new gold-based optical theranostics, Dalton Trans. 44 (2015) 4874-4883. doi:10.1039/C4DT02977A.

[68] M. Ali, L. Dondaine, A. Adolle, C. Sampaio, F. Chotard, P. Richard, F. Denat, A. Bettaieb, P. Le Gendre, V. Laurens, C. Goze, C. Paul, E. Bodio, Anticancer Agents: Does a Phosphonium Behave Like a Gold(I) Phosphine Complex? Let a "Smart" Probe Answer!, J. Med. Chem. 58 (2015) 4521-4528.

doi:10.1021/acs.jmedchem.5b00480. 
[69] M. Wenzel, A. de Almeida, E. Bigaeva, P. Kavanagh, M. Picquet, P. Le Gendre, E. Bodio, A. Casini, New Luminescent Polynuclear Metal Complexes with Anticancer Properties: Toward StructureActivity Relationships, Inorg. Chem. 55 (2016) 2544-2557. doi:10.1021/acs.inorgchem.5b02910.

[70] P.-E. Doulain, S. Tasan, R. Decreau, C. Paul, P. Le Gendre, F. Denat, C. Goze, E. Bodio, Toward the elaboration of new gold-based optical theranostics for in vivo imaging, J. Biol. Inorg. Chem. 19 (2014) S793-S793.

[71] S. Tasan, C. Licona, P.-E. Doulain, C. Michelin, C.P. Gros, P. Le Gendre, P.D. Harvey, C. Paul, C. Gaiddon, E. Bodio, Gold-phosphine-porphyrin as potential metal-based theranostics, JBIC J. Biol. Inorg. Chem. 20 (2014) 143-154. doi:10.1007/s00775-014-1220-8.

[72] V. Sancho, A. Di Florio, T.W. Moody, R.T. Jensen, Bombesin receptor-mediated imaging and cytotoxicity: review and current status, Curr. Drug Deliv. 8 (2011) 79-134.

[73] S.A. Hilderbrand, R. Weissleder, Near-infrared fluorescence: application to in vivo molecular imaging, Curr. Opin. Chem. Biol. 14 (2010) 71-79. doi:10.1016/j.cbpa.2009.09.029.

[74] Y. Liu, Z. Li, L. Chen, Z. Xie, Near infrared BODIPY-Platinum conjugates for imaging, photodynamic therapy and chemotherapy, Dyes Pigments. 141 (2017) 5-12.

doi:10.1016/j.dyepig.2017.01.075.

[75] P. Agostinis, K. Berg, K.A. Cengel, T.H. Foster, A.W. Girotti, S.O. Gollnick, S.M. Hahn, M.R. Hamblin, A. Juzeniene, D. Kessel, M. Korbelik, J. Moan, P. Mroz, D. Nowis, J. Piette, B.C. Wilson, J. Golab, Photodynamic therapy of cancer: an update, CA. Cancer J. Clin. 61 (2011) 250-281. doi:10.3322/caac.20114.

[76] A. Kamkaew, S. Hui Lim, H. Boon Lee, L. Voon Kiew, L. Yong Chung, K. Burgess, BODIPY dyes in photodynamic therapy, Chem. Soc. Rev. 42 (2013) 77-88. doi:10.1039/C2CS35216H.

[77] W. Wu, H. Guo, W. Wu, S. Ji, J. Zhao, Organic Triplet Sensitizer Library Derived from a Single Chromophore (BODIPY) with Long-Lived Triplet Excited State for Triplet-Triplet Annihilation Based Upconversion, J. Org. Chem. 76 (2011) 7056-7064. doi:10.1021/jo200990y.

[78] L. Huang, J. Zhao, Iodo-Bodipys as visible-light-absorbing dual-functional photoredox catalysts for preparation of highly functionalized organic compounds by formation of $\mathrm{C}-\mathrm{C}$ bonds via reductive and oxidative quenching catalytic mechanisms, RSC Adv. 3 (2013) 23377-23388. doi:10.1039/C3RA43299H.

[79] A. Bhattacharyya, A. Dixit, S. Banerjee, B. Roy, A. Kumar, A.A. Karande, A.R. Chakravarty, BODIPY appended copper(II) complexes for cellular imaging and singlet oxygen mediated anticancer activity in visible light, RSC Adv. 6 (2016) 104474-104482. doi:10.1039/C6RA23118G.

[80] A. Bhattacharyya, A. Dixit, K. Mitra, S. Banerjee, A.A. Karande, A.R. Chakravarty, BODIPY appended copper(II) complexes of curcumin showing mitochondria targeted remarkable photocytotoxicity in visible light, MedChemComm. 6 (2015) 846-851. doi:10.1039/C4MD00425F.

[81] D.R. Rice, H. Gan, B.D. Smith, Bacterial imaging and photodynamic inactivation using zinc(II)dipicolylamine BODIPY conjugates, Photochem. Photobiol. Sci. 14 (2015) 1271-1281. doi:10.1039/C5PP00100E.

[82] T. Wang, Y. Hou, Y. Chen, K. Li, X. Cheng, Q. Zhou, X. Wang, Two novel BODIPY-Ru(II) arene dyads enabling effective photo-inactivation against cancer cells, Dalton Trans. 44 (2015) 1272612734. doi:10.1039/C5DT01612F. 
[83] W. Wang, L. Wang, Z. Li, Z. Xie, BODIPY-containing nanoscale metal-organic frameworks for photodynamic therapy, Chem. Commun. 52 (2016) 5402-5405. doi:10.1039/C6CC01048B.

[84] X.-J. Jiang, J.T.F. Lau, Q. Wang, D.K.P. Ng, P.-C. Lo, pH- and Thiol-Responsive BODIPYBased Photosensitizers for Targeted Photodynamic Therapy, Chem. - Eur. J. 22 (2016) 8273-8281. doi:10.1002/chem.201600452.

[85] T. Zhang, L. Wang, C. Ma, W. Wang, J. Ding, S. Liu, X. Zhang, Z. Xie, BODIPY-containing nanoscale metal-organic frameworks as contrast agents for computed tomography, J. Mater. Chem. B. 5 (2017) 2330-2336. doi:10.1039/C7TB00392G.

[86] M. Üçüncü, E. Karakuş, E. Kurulgan Demirci, M. Sayar, S. Dartar, M. Emrullahoğlu, BODIPY$\mathrm{Au}(\mathrm{I})$ : A Photosensitizer for Singlet Oxygen Generation and Photodynamic Therapy, Org. Lett. 19 (2017) 2522-2525. doi:10.1021/acs.orglett.7b00791.

[87] E. Palao, R. Sola-Llano, A. Tabero, H. Manzano, A.R. Agarrabeitia, A. Villanueva, I. LópezArbeloa, V. Martínez-Martínez, M.J. Ortiz, AcetylacetonateBODIPY-Biscyclometalated Iridium(III) Complexes: Effective Strategy towards Smarter Fluorescent Photosensitizer Agents, Chem. - Eur. J. 23 (2017) 10139-10147. doi:10.1002/chem.201701347.

[88] L. Tabrizi, H. Chiniforoshan, New cyclometalated Ir(III) complexes with NCN pincer and mesophenylcyanamide BODIPY ligands as efficient photodynamic therapy agents, RSC Adv. 7 (2017) 34160 34169. doi:10.1039/C7RA05579J.

[89] P. Majumdar, X. Yuan, S. Li, B.L. Guennic, J. Ma, C. Zhang, D. Jacquemin, J. Zhao, Cyclometalated Ir(III) complexes with styryl-BODIPY ligands showing near IR absorption/emission: preparation, study of photophysical properties and application as photodynamic/luminescence imaging materials, J. Mater. Chem. B. 2 (2014) 2838-2854. doi:10.1039/C4TB00284A.

[90] L. Zou, H. Wang, B. He, L. Zeng, T. Tan, H. Cao, X. He, Z. Zhang, S. Guo, Y. Li, Current Approaches of Photothermal Therapy in Treating Cancer Metastasis with Nanotherapeutics, Theranostics. 6 (2016) 762-772. doi:10.7150/thno.14988.

[91] W.-L. Lu, Y.-Q. Lan, K.-J. Xiao, Q.-M. Xu, L.-L. Qu, Q.-Y. Chen, T. Huang, J. Gao, Y. Zhao, BODIPY-Mn nanoassemblies for accurate MRI and phototherapy of hypoxic cancer, J. Mater. Chem. B. 5 (2017) 1275-1283. doi:10.1039/C6TB02575G.

[92] A. Louie, Multimodality Imaging Probes: Design and Challenges, Chem. Rev. 110 (2010) 31463195. doi:10.1021/cr9003538.

[93] U. Seibold, B. Wängler, R. Schirrmacher, C. Wängler, Bimodal Imaging Probes for Combined PET and OI: Recent Developments and Future Directions for Hybrid Agent Development, BioMed Res. Int. 2014 (2014) 1-13. doi:10.1155/2014/153741.

[94] G.M. van Dam, G. Themelis, L.M.A. Crane, N.J. Harlaar, R.G. Pleijhuis, W. Kelder, A. Sarantopoulos, J.S. de Jong, H.J.G. Arts, A.G.J. van der Zee, J. Bart, P.S. Low, V. Ntziachristos, Intraoperative tumor-specific fluorescence imaging in ovarian cancer by folate receptor- $\alpha$ targeting: first in-human results, Nat. Med. 17 (2011) 1315-1319. doi:10.1038/nm.2472.

[95] Z. Li, T.-P. Lin, S. Liu, C.-W. Huang, T.W. Hudnall, F.P. Gabbaï, P.S. Conti, Rapid aqueous [18F]-labeling of a bodipy dye for positron emission tomography/fluorescence dual modality imaging, Chem. Commun. 47 (2011) 9324. doi:10.1039/c1cc13089g. 
[96] J.A. Hendricks, E.J. Keliher, D. Wan, S.A. Hilderbrand, R. Weissleder, R. Mazitschek, Synthesis of $\left[{ }^{18}\right.$ F]BODIPY: Bifunctional Reporter for Hybrid Optical/Positron Emission Tomography Imaging, Angew. Chem. Int. Ed. 51 (2012) 4603-4606. doi:10.1002/anie.201107957.

[97] S. Liu, T.-P. Lin, D. Li, L. Leamer, H. Shan, Z. Li, F.P. Gabbaï, P.S. Conti, Lewis Acid-Assisted Isotopic ${ }^{18} \mathrm{~F}-{ }^{19} \mathrm{~F}$ Exchange in BODIPY Dyes: Facile Generation of Positron Emission Tomography/Fluorescence Dual Modality Agents for Tumor Imaging, Theranostics. 3 (2013) 181-189. doi:10.7150/thno.5984.

[98] S. Liu, D. Li, H. Shan, F.P. Gabbaï, Z. Li, P.S. Conti, Evaluation of 18F-labeled BODIPY dye as potential PET agents for myocardial perfusion imaging, Nucl. Med. Biol. 41 (2014) 120-126. doi:10.1016/j.nucmedbio.2013.09.006.

[99] K. Chansaenpak, H. Wang, M. Wang, B. Giglio, X. Ma, H. Yuan, S. Hu, Z. Wu, Z. Li, Synthesis and Evaluation of $\left[{ }^{18} \mathrm{~F}\right.$-Ammonium BODIPY Dyes as Potential Positron Emission Tomography Agents for Myocardial Perfusion Imaging, Chem. - Eur. J. 22 (2016) 12122-12129. doi:10.1002/chem.201601972.

[100] K. Chansaenpak, M. Wang, H. Wang, Z. Wu, Z. Li, Evaluation of [18F]-ammonium BODIPY dyes as potential PET radiotracers for myocardial perfusion imaging, J. Nucl. Med. 57 (2016) 1227-1227.

[101] C.P. Ortmeyer, G. Haufe, K. Schwegmann, S. Hermann, M. Schäfers, F. Börgel, B. Wünsch, S. Wagner, V. Hugenberg, Synthesis and evaluation of a [ 18 F]BODIPY-labeled caspase-inhibitor, Bioorg. Med. Chem. 25 (2017) 2167-2176. doi:10.1016/j.bmc.2017.02.033.

[102] C. Bernhard, C. Goze, Y. Rousselin, F. Denat, First bodipy-DOTA derivatives as probes for bimodal imaging, Chem. Commun. 46 (2010) 8267. doi:10.1039/c0cc02749a.

[103] C. Bernhard, M. Moreau, D. Lhenry, C. Goze, F. Boschetti, Y. Rousselin, F. Brunotte, F. Denat, DOTAGA-Anhydride: A Valuable Building Block for the Preparation of DOTA-Like Chelating Agents, Chem. - Eur. J. 18 (2012) 7834-7841. doi:10.1002/chem.201200132.

[104] D. Lhenry, M. Larrouy, C. Bernhard, V. Goncalves, O. Raguin, P. Provent, M. Moreau, B. Collin, A. Oudot, J.-M. Vrigneaud, F. Brunotte, C. Goze, F. Denat, BODIPY: A Highly Versatile Platform for the Design of Bimodal Imaging Probes, Chem. - Eur. J. 21 (2015) 13091-13099.

doi:10.1002/chem.201501676.

[105] V. Duheron, M. Moreau, B. Collin, W. Sali, C. Bernhard, C. Goze, T. Gautier, J.-P. Pais de Barros, V. Deckert, F. Brunotte, L. Lagrost, F. Denat, Dual Labeling of Lipopolysaccharides for SPECTCT Imaging and Fluorescence Microscopy, ACS Chem. Biol. 9 (2014) 656-662. doi:10.1021/cb400779j.

[106] N. Maindron, M. Ipuy, C. Bernhard, D. Lhenry, M. Moreau, S. Carme, A. Oudot, B. Collin, J.-M. Vrigneaud, P. Provent, F. Brunotte, F. Denat, C. Goze, Near-Infrared-Emitting BODIPY-trisDOTA ${ }^{111}$ In as a Monomolecular Multifunctional Imaging Probe: From Synthesis to In Vivo Investigations, Chem. Eur. J. 22 (2016) 12670-12674. doi:10.1002/chem.201602886.

[107] L.G. Meimetis, E. Boros, J.C. Carlson, C. Ran, P. Caravan, R. Weissleder, Bioorthogonal Fluorophore Linked DFO - Technology Enabling Facile Chelator Quantification and Multimodal Imaging of Antibodies, Bioconjug. Chem. 27 (2016) 257-263. doi:10.1021/acs.bioconjchem.5b00630.

[108] S.D. Topel, Ö. Topel, R.B. Bostancioğlu, A.T. Koparal, Synthesis and characterization of Bodipy functionalized magnetic iron oxide nanoparticles for potential bioimaging applications, Colloids Surf. B 
Biointerfaces. 128 (2015) 245-253. doi:10.1016/j.colsurfb.2015.01.043.

[109] E. Portnoy, B. Polyak, D. Inbar, G. Kenan, A. Rai, S.L. Wehrli, T.P.L. Roberts, A. Bishara, A. Mann, M. Shmuel, K. Rozovsky, G. Itzhak, T. Ben-Hur, S. Magdassi, D. Ekstein, S. Eyal, Tracking inflammation in the epileptic rat brain by bi-functional fluorescent and magnetic nanoparticles, Nanomedicine Nanotechnol. Biol. Med. 12 (2016) 1335-1345. doi:10.1016/j.nano.2016.01.018.

[110] D. Boison, W.-L. Lu, Q.-M. Xu, H. Yang, T. Huang, Q.-Y. Chen, J. Gao, Y. Zhao, A mitochondria targeting Mn nanoassembly of BODIPY for LDH-A, mitochondria modulated therapy and bimodal imaging of cancer, Colloids Surf. B Biointerfaces. 147 (2016) 387-396.

doi:10.1016/j.colsurfb.2016.08.024.

[111] M. Ceulemans, K. Nuyts, W. De Borggraeve, T. Parac-Vogt, Gadolinium(III)-DOTA Complex Functionalized with BODIPY as a Potential Bimodal Contrast Agent for MRI and Optical Imaging, Inorganics. 3 (2015) 516-533. doi:10.3390/inorganics3040516.

[112] E.-J. Kim, S. Bhuniya, H. Lee, H.M. Kim, W.S. Shin, J.S. Kim, K.S. Hong, In Vivo Tracking of Phagocytic Immune Cells Using a Dual Imaging Probe with Gadolinium-Enhanced MRI and NearInfrared Fluorescence, ACS Appl. Mater. Interfaces. 8 (2016) 10266-10273. doi:10.1021/acsami.6b03344.

[113] P. Kos, H. Plenio, Metal Complexes of a Boron-Dipyrromethene (BODIPY)-Tagged NHeterocyclic Carbene (NHC) as Luminescent Carbon Monoxide Chemodosimeters, Chem. - Eur. J. 21 (2015) 1088-1095. doi:10.1002/chem.201405316.

[114] R. Vasiuta, H. Plenio, Observing Initial Steps in Gold-Catalyzed Alkyne Transformations by Utilizing Bodipy-Tagged Phosphine-Gold Complexes, Chem. - Eur. J. 22 (2016) 6353-6360. doi:10.1002/chem.201600264.

[115] A.M. Lifschitz, C.M. Shade, A.M. Spokoyny, J. Mendez-Arroyo, C.L. Stern, A.A. Sarjeant, C.A. Mirkin, Boron-Dipyrromethene-Functionalized Hemilabile Ligands as "Turn-On" Fluorescent Probes for Coordination Changes in Weak-Link Approach Complexes, Inorg. Chem. 52 (2013) 5484-5492. doi:10.1021/ic400383t.

[116] A.M. Lifschitz, R.M. Young, J. Mendez-Arroyo, V.V. Roznyatovskiy, C.M. McGuirk, M.R. Wasielewski, C.A. Mirkin, Chemically regulating Rh(I)-Bodipy photoredox switches, Chem. Commun. 50 (2014) 6850-6852. doi:10.1039/C4CC01345J. 